\title{
Importance of $\mathrm{Ca}^{2+-d e p e n d e n t ~ t r a n s a m i d a t i o n ~ a c t i v i t y ~ i n ~ t h e ~}$ protection afforded by tissue transglutaminase against doxorubicin-induced apoptosis
}

\author{
Sunando Datta ${ }^{\ddagger}, \perp$, Marc A. Antonyak $\S, \perp$, and Richard A. Cerione ${ }^{\ddagger}, \S,{ }^{\star}$ \\ \$Department of Chemistry and Chemical Biology, Cornell University, Ithaca, NY 14853 \\ §Department of Molecular Medicine, Cornell University, Ithaca, NY 14853
}

\section{Abstract}

Tissue transglutaminase II (TGase-II), which is capable of both GTP-binding and transamidation activities, has been implicated in a variety of biological disorders ranging from cancer to neurodegenerative diseases. Recent studies have suggested that the transamidation activity of TGaseII is necessary for the survival of cancer cells confronted with different stresses and cellular insults. When assayed in vitro, the transamidation activity of TGase-II is $\mathrm{Ca}^{2+}$-dependent. However, at present little is known regarding how the regulation by $\mathrm{Ca}^{2+}$ is manifested or if in fact it is important for the cellular functions of TGase-II. Here, we have set out to further examine the $\mathrm{Ca}^{2+}$-mediated regulation of TGase-II's transamidation activity, with our goals being to identify the $\mathrm{Ca}^{2+}$-regulatory sites on the protein and determine whether they are essential for TGase-II to confer survival to human breast cancer cells. Based on comparisons between the X-ray crystal structures for TGase-II and TGase-III, we identified three putative $\mathrm{Ca}^{2+}$-regulatory sites on TGase-II. Site-directed mutagenesis was performed to individually alter key residues at each of the sites. These substitutions did not affect the ability of TGase-II to bind guanine nucleotides, nor did they cause any obvious changes in its cellular localization. While substitutions at the different $\mathrm{Ca}^{2+}$-regulatory sites could either slightly enhance or markedly reduce the GTP hydrolytic activity of TGase-II, mutations at each of the three sites inhibited the $\mathrm{Ca}^{2+}$-responsive transamidation activity. We further showed that the same substitutions inhibited the ability of TGase-II to protect human breast cancer cells against the apoptotic activity of doxorubicin. Overall, these findings demonstrate that the $\mathrm{Ca}^{2+}$-mediated regulation of transamidation activity is essential for the ability of TGase-II to confer cell survival.

Tissue transglutaminase II (TGase-II) is a member of a family of acyl transferases that catalyze the $\mathrm{Ca}^{2+}$-dependent formation of an amide bond between $\gamma$-carboxamide groups of peptidebound glutamine residues and either the $\varepsilon$-amino groups of lysine residues in proteins or the amino groups from polyamines (i.e. transamidation) (1-3). The ability of TGase-II to exhibit transamidation activity could explain its role in a number of physiological processes and disease states including cell adhesion and migration, bone formation, apoptosis, cell survival, neurodegenerative disorders such as Alzheimer's and Huntington's diseases, Celiac's disease, and cancer (4-16). However, the ability of TGase-II to bind guanine nucleotides has also received a good deal of attention because of its potential implications for cellular signaling events. TGase-II was the first member of the transglutaminase family shown to bind and hydrolyze GTP and thus to be capable of acting as a molecular switch, along the lines of the well-known signaling GTP-binding proteins (G proteins) (17-19). Indeed, TGase-II was

*To whom correspondence should be addressed. E-mail: rac1 @ cornell.edu, tel: (607) 253-3888, fax: (607) 253-3659.

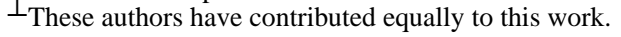


identified as the $\mathrm{G}$ protein (originally called $\mathrm{Gh}$ ) responsible for linking $\alpha 1$-adrenergic receptors to the stimulation of phospholipase $\mathrm{C} \delta$ in hepatocytes $(20,21)$. More recently, the GTP-binding activity of TGase-II has been suggested to play an important role in its ability to confer a survival advantage to cells treated with apoptotic agents (14).

The X-ray crystal structures for TGase-II and the highly related TGase-III have provided important insights into how these proteins are able to bind guanine nucleotides $(22,23)$. However, significantly less is known regarding the detailed catalytic mechanism underlying the acyl-transferase (transamidation) activity, or the nature of the reciprocal regulation that has been observed between guanine nucleotide binding to TGase-II and its ability to catalyze the transamidation of substrates. The binding of guanine nucleotides to TGase-II negatively regulates its transamidation activity, although, there have been conflicting suggestions as to whether or not GTP and GDP are equipotent regulators of the enzymatic activity $(18,24,25)$. An additional and potentially important regulatory feature of transamidation activity involves the interaction of $\mathrm{Ca}^{2+}$ with TGase-II. Millimolar levels of $\mathrm{Ca}^{2+}$ have been reported to be necessary for assaying the transamidation activity of TGase-II in vitro (2). Moreover, the binding of $\mathrm{Ca}^{2+}$ by TGase-II appears to weaken its affinity for guanine nucleotides (18), raising the possibility that the negative regulation by $\mathrm{Ca}^{2+}$ of guanine nucleotide-binding activity might help contribute to its ability to stimulate transamidation. Still, these requirements for $\mathrm{Ca}^{2+}$ are somewhat puzzling because some of the cellular functions of TGase-II likely occur at intracellular sites (e.g. the cytosol and nucleus). Thus far, a direct examination of the importance of TGase-II-Ca ${ }^{2+}$ interactions to the cellular function of this GTP-binding protein/ acyl transferase has not been performed.

In the present study, we have set out to take a closer look at the regulation exerted by $\mathrm{Ca}^{2+}$ on transamidation activity and to assess its importance for the ability of TGase-II to confer cell survival. Three $\mathrm{Ca}^{2+}$-binding sites were identified based on the X-ray crystal structure for TGase-III (23). These sites are conserved in the related TGase-II molecule, which then afforded us the opportunity to make changes at these sites and examine their impact on different aspects of TGase-II function including its transamidation activity. We found that introducing mutations at each of the $\mathrm{Ca}^{2+}$-binding sites had little effect on the guanine nucleotide-binding activity nor did they cause obvious changes in the cellular localization of TGase-II. While the mutations exhibited differential effects on the ability of TGase-II to hydrolyze GTP (i.e. two of the mutations slightly stimulated the activity and the other significantly inhibited it), all three clearly compromised its transamidation activity. We went on to show that inhibition of the $\mathrm{Ca}^{2+}$-mediated regulation of transamidation activity affected the ability of TGase-II to confer survival to human breast cancer cells challenged with a chemotherapeutic agent.

\section{EXPERIMENTAL PROCEDURES}

\section{Site-directed mutagenesis}

All TGase-II mutants were generated by using a PCR-based mutagenesis method (Quickchange mutation kit, Stratagene). For each mutant, a pair of oligonucleotide primers containing the desired mutagenesis was used for the PCR reaction. The parental strand was removed by DpnI digestion before transformation into Escherichia coli strain DH5 $\alpha$. Mutations were verified by sequence analysis at the Bio-Resource Center of Cornell University.

\section{Expression and purification of recombinant wild-type and mutated TGase-II proteins}

The cDNAs encoding human wild-type TGase-II and the different TGase-II mutants were subcloned into the pET-28a vector (Novagen) to express these recombinant proteins with an N-terminal 6-histidine ( His $_{6}$ ) tag. Overnight cultures from colonies of Escherichia coli BL21 (DE3) cells (Novagen) transformed with the expression vectors were grown at $37^{\circ} \mathrm{C}$. These 
were used to inoculate 1 liter of medium containing $2 \%$ bacto-tryptone, $1.5 \%$ yeast extract, $0.2 \% \mathrm{Na}_{2} \mathrm{HPO}_{4}, 0.1 \% \mathrm{KH}_{2} \mathrm{PO}_{4}, 0.8 \% \mathrm{NaCl}$, and $0.2 \%$ glucose (all wt/vol). The bacterial cells were then grown at $37^{\circ} \mathrm{C}$ until the cell density reached an $\mathrm{OD}_{600}$ reading of 0.6 , at which point the temperature was reduced from $37^{\circ} \mathrm{C}$ to $25^{\circ} \mathrm{C}$ before induction with $10 \mu \mathrm{M}$ isopropyl $\beta$-Dthiogalactoside (IPTG). The cultures were grown overnight at $25^{\circ} \mathrm{C}$ and then the cells were harvested by centrifugation at $4^{\circ} \mathrm{C}$. Cell pellets from 3 liters of culture were lysed by sonication in $100 \mathrm{ml}$ of lysis buffer ( $50 \mathrm{mM} \mathrm{Na}_{2} \mathrm{HPO}_{4}, \mathrm{pH} 7.5,100 \mathrm{mM} \mathrm{NaCl}, 5 \mathrm{mM}$ benzamidine) with $100 \mu \mathrm{M}$ GDP, $50 \mu \mathrm{M}$ ATP and $50 \mu \mathrm{g} / \mathrm{ml} \mathrm{PMSF}$. After sonication, cell debris were removed by high-speed centrifugation and the supernatant was loaded onto a column containing $5 \mathrm{ml}$ of Ni-NTA metal-affinity resins (Pharmacia Biotech). The column was washed with $100 \mathrm{ml}$ of lysis buffer containing $100 \mu \mathrm{M}$ GDP and then further washed with $100 \mathrm{ml}$ of $20 \mathrm{mM}$ Hepes (pH 7.0), and $100 \mathrm{mM} \mathrm{NaCl}$. The His-tagged TGase-II fusion proteins were eluted with 20 $\mathrm{mM}$ Hepes (pH 7.0), $25 \mathrm{mM} \mathrm{NaCl}$, and $160 \mathrm{mM}$ imidazole. The eluted proteins were loaded onto a MonoQ anion-exchange column (Pharmacia Biotech) equilibrated with $50 \mathrm{mM}$ Mes (pH 6.5), $25 \mathrm{mM} \mathrm{NaCl}, 10 \%$ (vol/vol) glycerol, and $2 \mathrm{mM}$ DTT. After washing with the equilibration buffer, the recombinant TGase-II proteins were eluted by using a gradient of 25 $\mathrm{mM}$ to $800 \mathrm{mM} \mathrm{NaCl}$ in the same buffer. The fractions containing TGase-II were pooled and concentrated to $10 \mathrm{ml}$ by using UltraPrep filtration (Millipore, molecular weight cutoff = 30,000 ), and then loaded onto a HiLoad 26/60 Superdex S-200 gel filtration column (Pharmacia Biotech) and eluted with $20 \mathrm{mM}$ Hepes (pH 7.0), $100 \mathrm{mM} \mathrm{NaCl}, 10 \%$ (vol/vol) glycerol, and $2 \mathrm{mM}$ DTT at $2.0 \mathrm{ml} / \mathrm{min}$. Fractions containing the TGase-II proteins were pooled and concentrated.

\section{Comparisons of the X-ray structures of TGase-II and TGase-III}

The TGase-III structure containing $3 \mathrm{Ca}^{2+}$ ions (PDBID: 1L9N) was analyzed for this study (23). Contacts for each of the $\mathrm{Ca}^{2+}$ ions were calculated using the "CONTACT" program from the CCP4 suite of programs with a distance cut-off of 3.6 $\AA$. Corresponding residues in TGaseII were identified by aligning its sequence with that of TGase-III. The possible contacts made by the $\mathrm{Ca}^{2+}$ ions with TGase-II were also determined. For this purpose, the TGase-II structure (1KV3) (22) was superimposed onto that for TGase-III.

\section{Fluorescence measurements}

All fluorescence measurements were performed using a Varian eclipse spectrofluorimeter. The experiments were carried out in $50 \mathrm{mM}$ Tris-HCl buffer, $\mathrm{pH} 7.5$, containing $2 \mathrm{mM}$ DTT and $1 \mathrm{mM}$ EDTA. The excitation and emission wavelengths for BODIPY fluorescence were set at $504 \mathrm{~nm}$ and $520 \mathrm{~nm}$, respectively.

\section{GTP hydrolysis assays}

Wild-type TGase-II or the different TGase-II mutants were assayed for GTP hydrolytic activity using $\left[\gamma^{32} \mathrm{P}\right] \mathrm{GTP}$ in a buffer containing $200 \mathrm{mM}$ MOPS (Sigma), pH 7.3, $2 \mathrm{mM} \mathrm{MgCl}_{2}, 100$ $\mu \mathrm{M}$ EDTA, and $2 \mathrm{mM}$ DTT. The assays were initiated by the addition of $\left[\gamma^{32} \mathrm{P}\right] \mathrm{GTP}$ (final concentration $=10 \mu \mathrm{M}$; specific activity $=5 \mathrm{Ci} / \mathrm{mmol})$. Aliquots $(50 \mu \mathrm{l})$ were removed at specific time points and added to $750 \mu \mathrm{l}$ of $5 \%$ activated charcoal (neutralized) in $50 \mathrm{mM}$ $\mathrm{NaH}_{2} \mathrm{PO}_{4}$. The samples were centrifuged at high speed, and then aliquots of the supernatant $(40 \mu \mathrm{L})$ were removed and counted.

\section{Assays for transamidation activity}

The transamidation activities of purified, wild-type TGase-II and the different TGase-II mutants were measured using a spectrophotometric assay previously developed by Day and Keillor (26). In this assay, the deamidation of a glutamine substrate was coupled to a second reaction generating glutamate from $\gamma$-ketoglutarate with the oxidation of NADH to NAD. The 
oxidation of NADH was monitored in a Beckman DU200 spectrophotometer at $340 \mathrm{~nm}$. The standard assay contained $200 \mathrm{mM}$ MOPS, $\mathrm{pH} 7.3$, together with varying levels of $\mathrm{CaCl}_{2}$ (ranging from 1 to $20 \mathrm{mM}$ ), $250 \mu \mathrm{M}$ EDTA, $13 \mathrm{mM} \gamma$-ketoglutarate (Sigma), $260 \mu \mathrm{M} \mathrm{NADH,}$ $3 \mathrm{mM}$ methyl-lysine ester, 80 enzyme units of glutamate dehydrogenase (Sigma) and, unless otherwise indicated, $25 \mathrm{mM}$ benzyloxycarbonyl-glutaminylglycine (Z-Gln-Gly; Sigma) in a final volume of $400 \mu \mathrm{l}$. The reaction was started by adding recombinant TGase-II, and transamidation activity was monitored by measuring the change in absorbance at $340 \mathrm{~nm}$. The rate of the reaction was measured from the linear portion of the curve, using an extinction coefficient for NADH at $340 \mathrm{~nm}$ of $6220 \mathrm{M}^{-1} \mathrm{~cm}^{-1}$. All measurements were done at room temperature.

In some cases, the transamidation activities of wild-type TGase-II or the different TGase-II mutants expressed in cells were measured in cellular lysates. For these assays, whole cell extracts were incubated with transamidation reaction buffer $(20 \mathrm{mM} \mathrm{NaCl}, 20 \mathrm{mM}$ DTT) containing $2.5 \mathrm{mM} 5$-(Biotinamido)pentylamine and $20 \mathrm{mM} \mathrm{CaCl}_{2}$ for 10 minutes, and then the reactions were subjected to SDS-PAGE. The proteins were transferred to PVDF transfer membranes and blocked in BBST (100 mM boric acid, $20 \mathrm{mM}$ sodium borate, $0.01 \%$ SDS, $0.02 \%$ Tween 20 , and $80 \mathrm{mM} \mathrm{NaCl}$ ) containing $10 \%$ bovine serum albumin. The proteins that incorporated 5-(Biotinamido)pentylamine were detected using horseradish peroxidaseconjugated streptavidin followed by exposure to ECL (Amersham/GE Health Care).

\section{Cell culture}

SKBR3 cells were grown in RPMI 1640 medium (Invitrogen) containing 10\% fetal bovine serum and 100 units $/ \mathrm{ml}$ penicillin. The cell line was maintained in a humidified atmosphere with $5 \% \mathrm{CO}_{2}$ at $37^{\circ} \mathrm{C}$. To express the different TGase-II proteins in SKBR3 cells, Myc-tagged pcDNA3 constructs encoding the various TGase-II mutants were generated and transfected into cells using Lipofectamine (Invitrogen). About 24 hours following transfection, the cells were incubated in medium containing $0.5 \%$ serum for an additional 24 hours. Where indicated, vector-only transfected cells were stimulated with $100 \mathrm{ng} / \mathrm{ml}$ epidermal growth factor (EGF) (Invitrogen) and parental SKBR3 cells were exposed to various concentrations of doxorubicin (Sigma). All cell cultures were then rinsed with phosphate-buffered saline (PBS) and lysed with cell lysis buffer $\left(10 \mathrm{mM} \mathrm{Na}_{2} \mathrm{HPO}_{4}, 150 \mathrm{mM} \mathrm{NaCl}, 1 \%\right.$ Triton X-100, $0.5 \%$ sodium deoxycholate, $0.1 \%$ SDS, $0.004 \% \mathrm{NaF}_{1} 1 \mathrm{mM} \mathrm{NaVO}_{4}, 25 \mathrm{mM} \beta$-glycerophosphoric acid, and $1 \mu \mathrm{g} / \mathrm{ml}$ each of aprotinin and leupeptin). Equal concentrations of each cell lysate were subjected to SDS-PAGE and then the proteins were transferred to nitrocellulose. The filters were blocked with TBST ( $20 \mathrm{mM}$ Tris, $137 \mathrm{mM} \mathrm{NaCl}, \mathrm{pH} 7.4$, and $0.02 \%$ Tween 20) containing $7 \%$ nonfat dry milk, and then incubated with anti-Myc (Covance), anti-actin (Sigma), antiTGase-II (Neomarkers), anti-active Caspase-3 (Cell Signaling), and/or PARP (Santa Cruz) antibodies diluted in TBST. The primary antibodies were detected with horseradish peroxidaseconjugated secondary antibodies followed by exposure to ECL (Amersham Biosciences).

\section{Immunofluorescence and cell death assays}

SKBR3 cells plated on dual-chamber microscope slides (Nalge-Nunc) were cultured in medium containing $0.5 \%$ serum and increasing concentrations of doxorubicin for 24 hours and were then fixed with $3.7 \%$ formaldehyde. Cells plated on the microscope slides were also transfected with the different TGase-II expression constructs. Twenty-four hours following transfection, the cells were cultured in medium containing $0.5 \%$ serum \pm doxorubicin $(0.1$ $\mu \mathrm{M}$ or $\pm 0.2 \mu \mathrm{M}$ ) for an additional 24 hours and then fixed with $3.7 \%$ formaldehyde. The transfectants were permeabilized with PBS containing $0.2 \%$ Triton X-100, blocked with PBS containing 5\% bovine serum albumin, and then probed with anti-Myc antibody. The Myc antibody was detected with Oregon green 488-conjugated secondary antibody (Molecular 
Probes). All of the slides were incubated with DAPI to stain nuclei and the cells were then visualized by fluorescence microscopy. Cells undergoing apoptosis were identified by nuclear condensation or blebbing and the percentage of cell death was determined by calculating the ratio of apoptotic to non-apoptotic cells for each condition.

\section{RESULTS}

\section{Location of $\mathrm{Ca}^{2+}$-regulatory sites within TGase-II}

The transamidation activity of TGase-II has been suggested to be important for a number of its biological activities. Assays performed in vitro indicate that the transamidation activity requires $\mathrm{Ca}^{2+}$, suggesting that this divalent cation may have a key regulatory role in the different cellular functions performed by TGase-II. Thus, we wanted to determine whether by perturbing the binding of $\mathrm{Ca}^{2+}$ to TGase-II, we could disable its transamidation activity and negate its cellular actions. However, this first required knowledge of the location of the $\mathrm{Ca}^{2+}$-regulatory sites on TGase-II. Here we took advantage of the structural and functional similarities shared by TGase-II and TGase-III $(22,23)$, as these two members of the transglutaminase family are about $40 \%$ identical in their primary sequences, and the fact that the three major $\mathrm{Ca}^{2+}$-binding sites on TGase-III have been identified.

Comparisons of the X-ray crystal structures and primary sequences of these two proteins, together with the sequences for other members of the family that show $\mathrm{Ca}^{2+}$-dependent transamidation activity, revealed conserved amino acid residues that seemed most likely to serve as $\mathrm{Ca}^{2+}$-binding sites within TGase-II. Figure 1A shows these sequence comparisons, as well as depicts the locations of these sites, relative to the GTP-binding domain and the active site for transamidation activity. The potential interactions between $\mathrm{Ca}^{2+}$ ions and the amino acid residues within the three $\mathrm{Ca}^{2+}$-binding sites on TGase-II are depicted in Figure 1B. In order to examine the importance of these sites in the regulation of TGase-II activity, the following key residues within each of the interaction regions were mutated to alanine (these are highlighted in red in the sequence comparisons shown in Figure 1A).

Site 1-The first of the three $\mathrm{Ca}^{2+}$-binding sites in the primary sequence of TGase-II, designated site 1, consists of residues Gly226, Asn229, Asn231 and Asp233. Both Asn229 and Asp233 should be within $2.5 \AA$ from the $\mathrm{Ca}^{2+}$ ion, based on an analysis of the structure for TGase-III (see Table 1). Thus, we changed each of these residues to alanine.

Site 2-The second $\mathrm{Ca}^{2+}$-binding site on TGase-II consists of residues Asp306, Asn308, Asn310, Leu312 and Glu329. We selected Asp306 and Asn310 for mutation because based on the TGase-III structure, these residues should be in very close proximity to $\mathrm{Ca}^{2+}$ (Table 1).

Site 3-The third $\mathrm{Ca}^{2+}$-binding site consists of residues Asn398, Ser419, Glu447 and Glu452. Because Asn398 and Glu447 best matched our proximity criterion for binding $\mathrm{Ca}^{2+}$ (Table 1), we chose these residues for mutation. In addition to the corresponding residues being important for the binding of $\mathrm{Ca}^{2+}$ to TGase-III, the blood coagulation protein, Factor XIIIA, uses a similar set of residues to bind $\mathrm{Ca}^{2+}$, with substitutions at these sites reducing its transamidation activity by $\sim 80 \%$ (27).

\section{$\mathrm{Ca}^{2+}$-regulatory sites 1-3 do not influence the guanine nucleotide-binding activity of TGase- II}

As a first step toward examining whether substitutions at the $\mathrm{Ca}^{2+}$-regulatory sites affected the ability of guanine nucleotides to bind to TGase-II, we developed a fluorescence spectroscopic read-out for assaying nucleotide-binding activity. Histidine (His)-tagged TGase-II proteins were expressed in E. coli and purified through a series of chromatographic steps beginning 
with nickel affinity chromatography and then followed by anion exchange and size exclusion chromatography. This yielded highly purified preparations of wild-type TGase-II and each of the three TGase mutants that contained substitutions at the $\mathrm{Ca}^{2+}$-regulatory sites (Figure 2A, inset). We then took advantage of the fluorescence properties of the GTP-analog, BODIPYFL GTP $\gamma \mathrm{S}$ (BOD-GTP $\gamma$ ), to monitor the binding of guanine nucleotides to the recombinant TGase-II proteins under various conditions.

Figure 2A shows that BOD-GTP $\gamma \mathrm{S}$ was capable of a rapid binding interaction with wild-type TGase-II, as reflected by an immediate increase ( $\sim 2$ fold) in the fluorescence emission of the BODIPY moiety (dashed line). The enhanced fluorescence is due to an extension in the structure of the nucleotide analog that occurs upon its binding to proteins (e.g. TGase-II), thus eliminating the stacking between the BODIPY moiety and the guanine base and reducing its susceptibility to intramolecular quenching (28). Upon addition of GTP $\gamma \mathrm{S}$, the fluorescence enhancement was rapidly reversed, indicating that BOD-GTP $\gamma \mathrm{S}$ and GTP $\gamma \mathrm{S}$ freely and reversibly competed for a common guanine nucleotide-binding site on wild-type TGase-II.

The extent of the fluorescence enhancement was dependent on the percentage of recombinant TGase-II molecules that were purified without (pre-bound) GDP. Indeed, some of the recombinant wild-type TGase-II protein, upon isolation, existed in the GDP-bound state, based on HPLC analysis (data not shown) and as demonstrated by its X-ray crystal structure (22). Consequently, incubating wild-type TGase-II with alkaline phosphatase, which converted any bound GDP to GMP (that subsequently dissociated from the protein), resulted in a further enhancement in BOD-GTP $\gamma$ S fluorescence (Figure 2A, +AP), indicating that additional TGase-II molecules became available to bind the fluorescent nucleotide-analog.

Figure 2B shows the titration of wild-type TGase-II with BOD-GTP $\gamma \mathrm{S}$. The binding of the guanine nucleotide-analog to TGase-II was saturable and could be fit to a simple bimolecular reaction yielding an apparent dissociation constant of $385 \mathrm{nM}(+/-12 \mathrm{nM} ; \mathrm{n}=4)$. The ability of guanine nucleotides to compete with BOD-GTP $\gamma \mathrm{S}$ for binding to TGase-II allowed us to use this read-out to determine the apparent dissociation constants for GDP and GTP $\gamma \mathrm{S}$. As shown in Figure 2C, both GTP $\gamma$ S and GDP caused a dose-dependent quenching of the BODIPY fluorescence, as a result of competition for a common binding site on TGase-II. The best fits to these curves yielded apparent dissociation constants of $320 \mathrm{nM}(\mathrm{n}=3)$ and $1.5 \mu \mathrm{M}(\mathrm{n}=3)$ for GTP $\gamma$ S and GDP, respectively (Table 2).

Figures $3 \mathrm{~A}$ through $3 \mathrm{C}$ show the corresponding titrations for the competition between GTP $\gamma$ S and BOD-GTP $\gamma$ S obtained with each of the TGase-II double mutants that contained

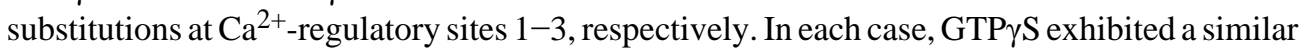
potency for competing with BOD-GTP $\gamma \mathrm{S}$ as was observed with wild-type TGase-II (Table 2). Thus, substitutions of key residues at each of the $\mathrm{Ca}^{2+}$-regulatory sites did not affect guanine nucleotide-binding activity.

\section{Substitutions at $\mathrm{Ca}^{2+}$-regulatory sites $1-3$ show differential effects on the GTP hydrolytic activity of TGase-II}

TGase-II also exhibits GTP hydrolytic activity, similar to the more traditional G protein signaling switches $(17,19,24)$. We therefore examined whether substitutions at the different $\mathrm{Ca}^{2+}$-regulatory sites influenced this activity. Interestingly, we found that the three $\mathrm{Ca}^{2+}$-site mutants did not exhibit identical effects when assaying their GTP hydrolytic capability. The site 1 mutant [TGase-II (N229A, D233A)] showed very poor GTP hydrolytic activity, as measured by ${ }^{32} \mathrm{Pi}$ release (Figure 4), despite its ability to fully bind GTP. On the other hand, the site 2 and site 3 mutants [i.e. TGase-II (D306A, N310A) and TGase-II (N398A, E447A), respectively] consistently showed slightly increased GTP hydrolytic activity compared to wildtype TGase-II. These results suggest that the site 1 substitutions cause TGase-II to adopt a 
different conformational state than do the other two classes of substitutions. The different conformational states apparently exert specific effects on the ability of TGase-II to reach the transition-state for the GTP hydrolytic activity. As will be discussed below, these findings provide us with some useful insights into the potential roles of GTP-binding and hydrolysis, versus transamidation activity, in the conferral of cell survival by TGase-II.

\section{$\mathrm{Ca}^{2+}$-regulatory sites 1-3 are important for the in vitro transamidation activity measured for recombinant TGase-II}

In order to examine the in vitro transamidation activity of the different TGase-II mutants, we used a coupled spectroscopic assay (see "Experimental Procedures"). In the case of wild-type TGase-II, there was no detectable transamidation activity when assayed in vitro in the absence of millimolar $\mathrm{Ca}^{2+}$ levels. Typically, full activity was achieved at $\sim 4 \mathrm{mM} \mathrm{Ca}^{2+}$. While it had previously been reported that the binding of guanine nucleotides to TGase-II inhibited its transamidation activity $(18,24,25)$, there has been some question as to whether both GTP and GDP are effective inhibitors. Figure 5A shows that the transamidation activity of wild-type TGase-II was inhibited by the non-hydrolyzable GTP analog, GTP $\gamma$ S, as well as by GDP. The dose-dependent inhibition by GTP $\gamma \mathrm{S}$ and GDP occurred at guanine nucleotide concentrations that were very similar to the dose-response profiles obtained with these nucleotides when assaying their abilities to compete with BOD-GTP $\gamma \mathrm{S}$ for binding to TGase-II (Figure 2C).

Figure $5 \mathrm{~B}$ shows the transamidation activities, measured as a function of $\mathrm{Ca}^{2+}$ concentration, for the different TGase-II mutants. Each of the mutants exhibited compromised $\mathrm{Ca}^{2+}$ dependent activity, indicating that $\mathrm{Ca}^{2+}$ interactions at sites $1-3$ are necessary for full transamidation capability. The $\mathrm{Ca}^{2+}$-dose response profiles were significantly shifted for the TGase-II (N229A, D233A) and TGase-II (N398A, E447A) mutants, suggesting that these substitutions significantly weakened $\mathrm{Ca}^{2+}$-binding at sites 1 and 3 , respectively. However, the TGase-II (D306A, N310A) mutant was completely inactive in transamidation assays. This might be explained by structural studies (23) showing that the binding of $\mathrm{Ca}^{2+}$ to the comparable site on TGase-III moves a loop region (i.e. corresponding to residues 325-330 in TGase-II) and thereby opens up a channel for substrates to properly access catalytic residues at the active site.

Figure 5C shows the results of in vitro transamidation assays of wild-type TGase-II and the different TGase-II mutants, when varying the concentration of the glutamine-containing substrate, Z-Gln-Gly, at a fixed level of $\mathrm{Ca}^{2+}(10 \mathrm{mM})$. The TGase-II (N229A, D233A) mutant showed an apparent weaker affinity for the substrate, compared to wild-type TGase-II, although extrapolating to high substrate concentrations suggests that the mutant would exhibit transamidation activity comparable to that for the wild-type protein. The site 2 mutant [TGaseII (D306A, N310A)] showed little or no activity over the entire range of substrate concentrations examined, consistent with the interpretation that this protein is catalytically defective, whereas the site 3 mutant [TGase-II (N398A, E447A)] showed a similar substrate dose-response profile as that obtained for wild-type TGase-II. However, at saturation, the final level of transamidation activity catalyzed by the site 3 mutant was only half that for the wildtype protein, consistent with the findings that this mutant showed only about half of the catalytic activity of the wild-type protein when assayed at $10 \mathrm{mM} \mathrm{Ca}^{2+}$ (Figure 5B).

\section{Effects of $\mathrm{Ca}^{2+}$-regulatory site mutations on TGase-II-catalyzed transamidation activity in whole cell lysates}

We then examined the abilities of Myc-tagged wild-type TGase-II and each of the different Myc-tagged TGase-II mutants, when expressed in human breast cancer (SKBR3) cells (Figure $6 \mathrm{~A}$, top panel), to catalyze the transamidation of proteins in whole-cell lysates (see

"Experimental Procedures"). As shown in Figure 6A (top panel), we were not able to detect 
endogenous TGase-II by Western blot analysis with anti-TGase-II antibody, except upon treatment with EGF which up-regulates its expression (16). However, we suspect that some endogenous TGase-II is present even under basal conditions, as suggested by the background levels of transamidation activity that are read-out by the crosslinking of lysate proteins to biotinylated pentylamine. The expression of Myc-tagged, wild-type TGase-II resulted in a significant increase in the transamidation of lysate proteins, compared to the basal activity observed in control cells (Figure 6B, bottom panel, see lanes 1 and 2; the top two panels show the relative expression of Myc-tagged, wild-type TGase-II and the different Myc-TGase-II mutants, and an actin-loading control). Under the same experimental conditions, each of the TGase-II mutants were less effective at catalyzing the transamidation of lysate proteins, compared to wild-type TGase-II (Figure 6B, bottom panel; see lanes 4-6 versus lane 2). This was especially the case for the TGase-II (D306A, N310A) and TGase-II (N398A, E447A) mutants, as they even reduced the basal levels of transamidation relative to what was detected in control (vector) cells (Figure 6B, bottom panel; compare lanes 5 and 6, respectively, with lane 1). The same was true for the TGase-II (C277V) mutant (compare lane 3 with lane 1), in which the essential active site cysteine residue was changed to valine. Thus, these mutants apparently are able to bind to some of the cellular substrates detected under basal conditions without stimulating their transamidation and thereby inhibit the reactions catalyzed by endogenous enzyme.

\section{Effects of $\mathrm{Ca}^{2+}$-regulatory site mutations on TGase-II-catalyzed protection against apoptotic stimuli}

Given the apparent ability of these different $\mathrm{Ca}^{2+}$-binding mutations to compromise TGaseII-catalyzed transamidation activity, we wanted to see what consequences these same substitutions had on the ability of TGase-II to exert its cellular functions. Previous work from our laboratory (14-16), as well as studies from other groups (29), has shown that TGase-II confers a survival advantage to cells challenged with apoptotic factors. We have recently shown that TGase-II plays an important role in EGF-mediated survival of human breast cancer cells and that it blocked the apoptotic activity accompanying the treatment of cells with doxorubicin (16). Thus, we compared the abilities of Myc-tagged wild-type TGase-II and the different TGase-II mutants to confer protection to SKBR3 cells following treatment with doxorubicin. Figure $6 \mathrm{C}$ shows that each of the Myc-tagged TGase-II mutants containing substitutions within the different $\mathrm{Ca}^{2+}$-binding sites exhibited a similar cytosolic distribution as that observed for wild-type TGase-II and the transamidation-defective TGase(C277V) mutant. Thus, our ability to perturb the $\mathrm{Ca}^{2+}$-regulatory sites of TGase-II did not significantly alter its cellular localization.

However, substitutions that impacted $\mathrm{Ca}^{2+}$-dependent transamidation activity did markedly influence the ability of TGase-II to promote cell survival. Figure 6D shows the dose-dependent apoptotic activity exhibited by doxorubicin in SKBR3 cells. The inset shows the corresponding effects of the drug on Caspase- 3 activation, both as read-out using a specific antibody for the activated caspase and by the degradation of the caspase-substrate PARP. Two different levels of doxorubicin that caused varying degrees of apoptosis were then chosen to examine the protective effects of wild-type TGase-II and the different $\mathrm{Ca}^{2+}$-binding site mutants (Figure $6 \mathrm{E})$. A significant protection against cell death was observed in SKBR3 cells, under both conditions of doxorubicin treatment, upon over-expressing wild-type TGase-II. As previously reported (16), expression of the TGase-II mutant [TGase $(\mathrm{C} 277 \mathrm{~V})]$ failed to provide any protection against the apoptotic activity of doxorubicin. The same was true when expressing each of the TGase-II mutants that contained substitutions at the $\mathrm{Ca}^{2+}$-regulatory sites. 


\section{DISCUSSION}

TGase-II is a dual function GTP-binding/acyl transferase that has been implicated in a variety of important biological outcomes (4-13). Perhaps foremost among these has been reports linking TGase-II to cell survival and cell death, where there have been contrasting views regarding whether TGase-II contributes (30-32) to or protects against (14-16) apoptotic challenges. Part of the confusion has likely arisen from the up-regulation of TGase-II expression and activity that accompanies the exposure of cells to stress or apoptotic factors. However, a good deal of evidence now supports the idea that TGase-II is typically up-regulated in response to various cellular insults as a protective measure, although in some cases, the excessive expression and/or mis-localization of TGase-II may ultimately have deleterious rather than beneficial effects. Recently, we have found that TGase-II plays a particularly important role in the survival of human breast cancer cells, with EGF treatment causing an increase in TGase-II expression and activation that may underlie the oncogenic potential and chemo-resistance of these cells (16).

The mechanisms by which TGase-II gives rise to cell survival are still largely unknown. Work from our laboratory showed that TGase-II protected NIH $3 \mathrm{~T} 3$ cells from the apoptotic effects of serum deprivation and that its GTP-binding capability may be sufficient to afford these protective effects (14). This raised the question as to whether TGase-II might function more in the capacity of a signaling $G$ protein, rather than as an acyl transferase, in mediating cell survival. Moreover, there have been questions concerning whether TGase-II was able to exhibit sufficient transamidation activity in cells to account for its survival function, since the normal levels of intracellular $\mathrm{Ca}^{2+}$ are well below the millimolar concentrations typically used when assaying enzymatic activity in vitro $(33,34)$. Subsequently, we found that TGase-II mutants containing substitutions at a cysteine residue (Cys277) thought to be essential for transamidation activity, were ineffective at protecting against apoptosis in fibroblasts and human breast cancer cells (14-16). However, there have been indications that mutation of this essential cysteine residue also negatively impacts GTP-binding activity (14), therefore making it difficult to use substitutions at this site to arrive at an unambiguous conclusion regarding the importance of transamidation activity in the survival functions of TGase-II. Likewise, while cystamine (as well as related compounds) has been used as a competitive inhibitor of the transamidation activity of TGase-II, questions have arisen regarding its specificity (35-37).

In the present study, we set out to take a closer look at the role of transamidation in the ability of TGase-II to confer cell survival activity to human breast cancer cells. In particular, we were interested in seeing whether mutations that perturbed the $\mathrm{Ca}^{2+}$-dependent regulation of transamidation activity of TGase-II influenced its ability to protect breast cancer cells against apoptotic challenges. We had previously proposed a possible location for a major $\mathrm{Ca}^{2+}$-binding site on TGase-II (22), based on the X-ray crystal structure for Factor XIIIa bound to $\mathrm{Ca}^{2+}$ (27). The X-ray crystal structure for $\mathrm{Ca}^{2+}$ bound to TGase-III (23), which is more similar to TGase-II, unambiguously identified the original site that we had suggested (now designated as site 3 on TGase-II), as well as two other $\mathrm{Ca}^{2+}$-binding sites (see Figures $1 \mathrm{~A}$ and $1 \mathrm{~B}$, and Table 1). We therefore mutated residues at each site and examined the effects of these substitutions on transamidation activity. Substitutions at site 2 had the most severe effects, resulting in no detectable transamidation activity at all $\mathrm{Ca}^{2+}$ and substrate concentrations examined, whereas mutations at sites 1 and 3 significantly shifted the dose-response curves for $\mathrm{Ca}^{2+}$ in our in vitro assays. When assaying the transamidation of lysate proteins, we found that the site 2 mutant reduced the basal levels of activity that arise from endogenous enzyme. The same was true for the TGase-II $(\mathrm{C} 227 \mathrm{~V})$ mutant which is thought to be catalytically dead. Apparently, these mutants can prevent endogenous TGase-II (or perhaps another transglutaminase present in the lysates) from acting on at least some of its cellular substrates. The site 3 mutant [TGase-II (N398A, E447A)] also reduced the basal levels of transamidation 
activity measured in the lysates, which was somewhat unexpected, because while this mutant is catalytically compromised, it still shows measurable in vitro activity when assayed using a spectrophotometric read-out. Thus, site 3 substitutions apparently have a more significant effect on the $\mathrm{Ca}^{2+}$-responsive transamidation activity of TGase-II toward cellular substrates, than would be predicted from the results of our in vitro assays. The site 1 mutant does not reduce the basal levels of transamidation activity, most likely because it exhibits a significantly weakened affinity for substrates and therefore would have little capability for blocking the interactions of endogenous enzymes with their cellular targets.

None of the substitutions at sites 1-3 negatively affected GTP-binding activity, based on our fluorescence measurements using BOD-GTP $\gamma \mathrm{S}$ (Table 2). Likewise, each of the TGase-II mutants showed a similar overall cellular localization as that observed for wild-type TGaseII. Interestingly, each of the $\mathrm{Ca}^{2+}$-binding site substitutions did affect GTP hydrolytic activity, although the effects were relatively minor for the site 2 and site 3 substitutions. These two mutations exhibited a slightly higher rate of GTP hydrolysis compared to wild-type TGase-II. On the other hand, substitutions at site 1 had a more dramatic effect, resulting in a significantly reduced hydrolytic activity. This suggests that $\mathrm{Ca}^{2+}$ interactions at site 1 may be necessary for inducing a conformational change that facilitates the development of the transition-state for GTP hydrolysis. A larger fraction of the cellular pool of TGase-II molecules with site 1 substitutions would therefore be expected to exist in the GTP-bound state. When analogous mutations are made in members of either the large or small $\mathrm{G}$ protein family, this gives rise to enhanced cellular signaling activities. However, the site 1 mutant behaves like the other TGaseII mutants in its inability to protect human breast cancer cells that have been challenged with doxorubicin, thereby suggesting that the GTP-binding status of TGase-II is not important for this survival response.

Overall, these findings lead us to make two important points. First, they verify that transamidation activity is in fact necessary for the protective effects conferred by TGase-II against apoptotic challenges to human breast cancer cells. This further supports the idea that the design of small molecule inhibitors of TGase-II's transamidation activity may represent a potentially useful strategy for intervention against certain human cancers (38-40). Secondly, our findings show that the $\mathrm{Ca}^{2+}$-mediated regulation of TGase-II is essential for its cellular function. The latter suggests that TGase-II may respond to micromolar levels of $\mathrm{Ca}^{2+}$ in a manner that generates sufficient transamidation activity to confer protective effects against apoptotic challenges. How this might occur is still not understood, although one interesting possibility is that other cellular proteins (i.e. binding partners for TGase-II), or even some cellular substrates, may increase the affinity of TGase-II for $\mathrm{Ca}^{2+}$. However, at present, we also cannot rule out the possibility that the ability to confer a survival advantage requires that TGase-II is secreted from cells $(41,42)$, enabling it to have access to higher (i.e. millimolar) levels of $\mathrm{Ca}^{2+}$.

We also are still left with the puzzle of how $\mathrm{Ca}^{2+}$ impacts the binding of guanine nucleotides to TGase-II. We find that millimolar levels of $\mathrm{Ca}^{2+}$ weaken the binding of guanine nucleotides to recombinant TGase-II by $\sim 5$-fold, as determined from our fluorescent read-out using BODGTP $\gamma$ S (data not shown). However, we have not been able to attribute the $\mathrm{Ca}^{2+}$-mediated negative regulation of guanine nucleotide-binding activity to any of the $\mathrm{Ca}^{2+}$-binding sites that have thus far been identified, which implies the existence of another site. This site may have a more general capability for binding divalent cations, as we have found that the affinity of TGase-II for guanine nucleotides can be enhanced by $\mathrm{Mg}^{2+}$, similar to what has been observed with some of the more traditional signaling $\mathrm{G}$ proteins, and that increasing (millimolar) levels of $\mathrm{Ca}^{2+}$ can negate the stimulatory effects of $\mathrm{Mg}^{2+}$ when assaying GTP-binding activity in vitro (S. Datta, unpublished data). It may be that under some conditions, $\mathrm{Ca}^{2+}$ can compete 
with $\mathrm{Mg}^{2+}$ for this regulatory site and antagonize, rather than promote, guanine nucleotidebinding interactions.

Finally, one of the more interesting questions for the future concerns the identification of the transamidation substrate(s) that is essential for conferring cell survival and protection against apoptosis. One intriguing possibility is Caspase- 3 , as it has recently been reported that TGaseII can catalyze the transamidation of this protease and inhibit its activity (43). We had earlier found that the Caspase-3-catalyzed degradation of the retinoblastoma $(\mathrm{Rb})$ gene product accompanies HPR-induced apoptosis in HL60 cells (15). Thus, future studies will be directed toward determining whether the prevention of caspase-catalyzed degradation of $\mathrm{Rb}$ represents a critical component in the ability of TGase-II to protect human breast cancer cells against chemotherapeutic challenges.

\section{Acknowledgements}

We would like to acknowledge Drs. Jon Erickson and Sekar Ramachandran for helpful discussions and Cindy Westmiller for expert secretarial assistance.

${ }^{\dagger}$ This work was supported by NIH grant GM61762.

\section{Abbreviations}

BOD-GTP $\gamma$ S, bodipy-FL modified form of GTP $\gamma$ S; DTT, dithiothreitol; G protein, GTPbinding protein; GTP $\gamma \mathrm{S}$, guanosine 5-0-(3-thiotriphosphate); PARP, poly(ADP-ribose) polymerase; TGase, transglutaminase..

\section{REFERENCES}

1. Folk JE. Transglutaminases. Annu. Rev. Biochem 1980;49:517-531. [PubMed: 6105840]

2. Greenberg CS, Birckbichler PJ, Rice RH. Transglutaminases: multifunctional cross-linking enzymes that stabilize tissues. FASEB J 1991;5:3071-3077. [PubMed: 1683845]

3. Aeschlimann D, Paulsson M. Transglutaminases: protein cross-linking enzymes in tissues and body fluids. Thromb. Haemostasis 1994;71:402-415. [PubMed: 7914385]

4. Aeschlimann D, Wetterwald A, Fleisch H, Paulsson M. Expression of tissue transglutaminase in skeletal tissues correlates with events of terminal differentiation of chondrocytes. J. Cell Biol 1993;120:1461-1470. [PubMed: 8095503]

5. Eitan S, Schwartz M. A transglutaminase that converts interleukin-2 into a factor cytotoxic to oligodendrocytes. Science 1993;261:106-108. [PubMed: 8100369]

6. Eitan S, Solomon A, Lavie V, Yoles E, Hirschberg DL, Belkin M, Schwartz M. Recovery of visual response of injured adult rat optic nerves treated with transglutaminase. Science 1994;264:1764-1768. [PubMed: 7911602]

7. Chiocca EA, Davies PJA, Stein JP. The molecular basis of retinoic acid action. Transcriptional regulation of tissue transglutaminase gene expression in macrophages. J. Biol. Chem 1988;263:1158411589. [PubMed: 2900242]

8. Bertram JS. Inhibition of neoplastic transformation in vitro by retinoids. Cancer Surv 1983;2:243-262.

9. Sporn MB, Roberts AB. Role of retinoids in differentiation and carcinogenesis. Cancer Res 1983;43:3034-3040. [PubMed: 6189589]

10. Piacentini M, Martinet N, Beninati S, Folk JE. Free and protein-conjugated polyamines in mouse epidermal cells. Effect of high calcium and retinoic acid. J. Biol. Chem 1988;263:3790-3794. [PubMed: 3346223]

11. Piacentini M, Fesus L, Farrace MG, Ghibelli L, Piredda L, Melino G. The expression of "tissue" transglutaminase in two human cancer cell lines is related with the programmed cell death (apoptosis). Eur. J. Cell Biol 1991;54:246-254. [PubMed: 1679009] 
12. Lesort M, Tucholski J, Miller ML, Johnson GVW. Tissue transglutaminase: a possible role in neurodegenerative diseases. Prog. Neurobiol 2000;61:439-463. [PubMed: 10748319]

13. Lorand L, Graham RM. Transglutaminases: crosslinking enzymes with pleiotropic functions. Nat. Rev. Mol. Cell Biol 2003;4:140-156. [PubMed: 12563291]

14. Antonyak MA, Singh US, Lee DA, Boehm JE, Combs C, Zgola MM, Page RL, Cerione RA. Effects of tissue transglutaminase on retinoic acid-induced cellular differentiation and protection against apoptosis. J. Biol. Chem 2001;276:33582-33587. [PubMed: 11438548]

15. Boehm JE, Singh U, Combs C, Antonyak MA, Cerione RA. Tissue transglutaminase protects against apoptosis by modifying the tumor suppressor protein p110 Rb. J. Biol. Chem 2002;277:2012720130. [PubMed: 11956182]

16. Antonyak MA, Miller AM, Jansen JM, Boehm JE, Balkman CE, Wakshlag JJ, Page RL, Cerione RA. Augmentation of tissue transglutaminase expression and activation by epidermal growth factor inhibit doxorubicin-induced apoptosis in human breast cancer cells. J. Biol. Chem 2004;279:4146141467. [PubMed: 15272014]

17. Fraij BM. GTP hydrolysis by human tissue transglutaminase homologue. Biochem. Biophys. Res. Commun 1996;218:45-49. [PubMed: 8573173]

18. Achyuthan KE, Greenberg CS. Identification of a guanosine triphosphate-binding site on guinea pig liver transglutaminase. Role of GTP and calcium ions in modulating activity. J. Biol. Chem 1987;262:1901-1906. [PubMed: 2879844]

19. Lee KN, Birckbichler PJ, Patterson MK. GTP hydrolysis by guinea pig liver transglutaminase. Biochem. Biophys. Res. Commun 1989;162:1370-1375. [PubMed: 2569868]

20. Feng J-F, Rhee SG, Im M-J. Evidence that phospholipase delta1 is the effector in the Gh (transglutaminase II)-mediated signaling. J. Biol. Chem 1996;271:16451-16454. [PubMed: 8663582]

21. Nakaoka H, Perez DM, Baek KJ, Das T, Husain AM, Misono K, Im MJ, Graham RM. Gh: a GTPbinding protein with transglutaminase activity and receptor signaling function. Science 1994;264:1593-1596. [PubMed: 7911253]

22. Liu S, Cerione RA, Clardy JC. Structural basis for the guanine nucleotide-binding activity of tissue transglutaminase and its regulation of transamidation activity. Proc. Natl. Acad. Sci 2002;99:27432747. [PubMed: 11867708]

23. Ahvazi B, Kim HC, Kee SH, Nemes Z, Steinert PM. Three-dimensional structure of the human transglutaminase 3 enzyme: binding of calcium ions changes structure for activation. EMBO J 2002;21:2055-2067. [PubMed: 11980702]

24. Singh US, Erickson JW, Cerione RA. Identification and biochemical characterization of an 80 kilodalton GTP-binding/transglutaminase from rabbit liver nuclei. Biochemistry 1995;34:1586315871. [PubMed: 7495818]

25. Lai TS, Slaughter TF, Peoples KA, Hettasch JM, Greenberg CS. Regulation of human tissue transglutaminase function by magnesium-nucleotide complexes. Identification of distinct binding sites for Mg-GTP and Mg-ATP. J. Biol. Chem 1998;273:1776-1781. [PubMed: 9430726]

26. Day N, Keillor JW. A continuous spectrophotometric linked enzyme assay for transglutaminase activity. Anal. Biochem 1999;274:141-144. [PubMed: 10527508]

27. Yee VC, Pedersen LC, Le Trong I, Bishop PD, Stenkamp RE, Teller DC. Three-dimensional structure of a transglutaminase: human blood coagulation factor XIII. Proc. Natl. Acad. Sci. USA 1994;91:7296-7300. [PubMed: 7913750]

28. McEwen DP, Gee KR, Kang HC, Neubig RR. Fluorescent BODIPY-GTP analogs: real-time measurement of nucleotide binding to G proteins. Anal. Biochem 2001;291:109-117. [PubMed: 11262163]

29. Tucholski J, Johnson GV. Tissue transglutaminase differentially modulates apoptosis in a stimulidependent manner. J. Neurochem 2002;81:780-791. [PubMed: 12065637]

30. Oliverio S, Amendola A, DiSano F, Farrace MG, Fesus L, Nemes Z, Piredda L, Spinedi A, Piacentini M. Tissue transglutaminase-dependent posttranslational modification of the retinoblastoma gene product in promonocytic cells undergoing apoptosis. Mol. Cell Biol 1997;17:6040-6048. [PubMed: 9315663] 
31. Melino G, Annicchiarico-Petruzzelli M, Piredda L, Candi E, Gentile V, Davies PJ, Piacentini M. Tissue transglutaminase and apoptosis: sense and antisense transfection studies with human neuroblastoma cells. Mol. Cell Biol 1994;14:6584-6596. [PubMed: 7935379]

32. Oliverio S, Amendola A, Rodolfo C, Spinedi A, Piacentini M. Inhibition of "tissue" transglutaminase increases cell survival by preventing apoptosis. J. Biol. Chem 1999;274:34123-34128. [PubMed: 10567382]

33. Lai TS, Bielawska A, Peoples KA, Hannun YA, Greenberg CS. Sphingosylphosphocholine reduces the calcium ion requirement for activating tissue transglutaminase. J. Biol. Chem 1997;272:1629516300. [PubMed: 9195933]

34. Smethurst PA, Griffin M. Measurement of tissue transglutaminase activity in a permeabilized cell system: its regulation by Ca2+ and nucleotides. Biochem. J 1996;313:803-808. [PubMed: 8611158]

35. Lesort M, Lee M, Tucholski J, Johnson GV. Cystamine inhibits caspase activity. Implications for the treatment of polyglutamine disorders. J. Biol. Chem 2003;278:3825-3830. [PubMed: 12458211]

36. Fox JH, Barber DS, Singh B, Zucker B, Swindell MK, Norflus F, Buzescu R, Chopra R, Ferrante RJ, Kazantsev A, Hersch SM. Cystamine increases L-cysteine levels in Huntington's disease transgenic mouse brain and in a PC12 model of polyglutamine aggregation. J. Neurochem 2004;91:413-422. [PubMed: 15447674]

37. Van Raamsdonk JM, Pearson J, Bailey CD, Rogers DA, Johnson GV, Hayden MR, Leavitt BR. Cystamine treatment is neuroprotective in the YAC128 mouse model of Huntington disease. J. Neurochem 2005;95:210-220. [PubMed: 16181425]

38. Yuan L, Choi K, Khosla C, Zheng X, Higashikubo R, Chicoine MR, Rich KM. Tissue transglutaminase 2 inhibition promotes cell death and chemosensitivity in glioblastomas. Mol. Cancer Ther 2005;4:1293-1302. [PubMed: 16170020]

39. Choi K, Siegel M, Piper JL, Yuan L, Cho E, Strnad P, Omary B, Rich KM, Khosla C. Chemistry and biology of dihydroisoxazole derivatives: selective inhibitors of human transglutaminase 2. Chem. Biol 2005;12:469-475. [PubMed: 15850984]

40. Keillor JW. Tissue transglutaminase inhibition. Chem. Biol 2005;12:469-475. [PubMed: 15850984]

41. Akimov SS, Krylov D, Fleischman LF, Belkin AM. Tissue transglutaminase is an integrin-binding adhesion coreceptor for fibronectin. J. Cell Biol 2000;148:825-838. [PubMed: 10684262]

42. Balklava Z, Verderio E, Collighan R, Gross S, Adams J, Griffin M. Analysis of tissue transglutaminase function in the migration of Swiss 3 T3 fibroblasts. J. Biol. Chem 2002;277:16567-16575. [PubMed: 11867617]

43. Yamaguchi H, Wang H-G. Tissue transglutaminase serves as an inhibitor of apoptosis by cross-linking caspase 3 in thapsigargin-treated cells. Mol. Cell Biol 2006;26:569-579. [PubMed: 16382148]

44. Thompson JD, Higgins DG, Gibson TJ. CLUSTAL W: improving the sensitivity of progressive multiple sequence alignment through sequence weighting, position-specific gap penalties and weight matrix choice. Nucleic Acids Res 1994;22:4673-4680. [PubMed: 7984417]

45. Kuzmic P. Program DYNAFIT for the analysis of enzyme kinetic data: application to HIV proteinase. Anal. Biochem 1996;237:260-273. [PubMed: 8660575] 


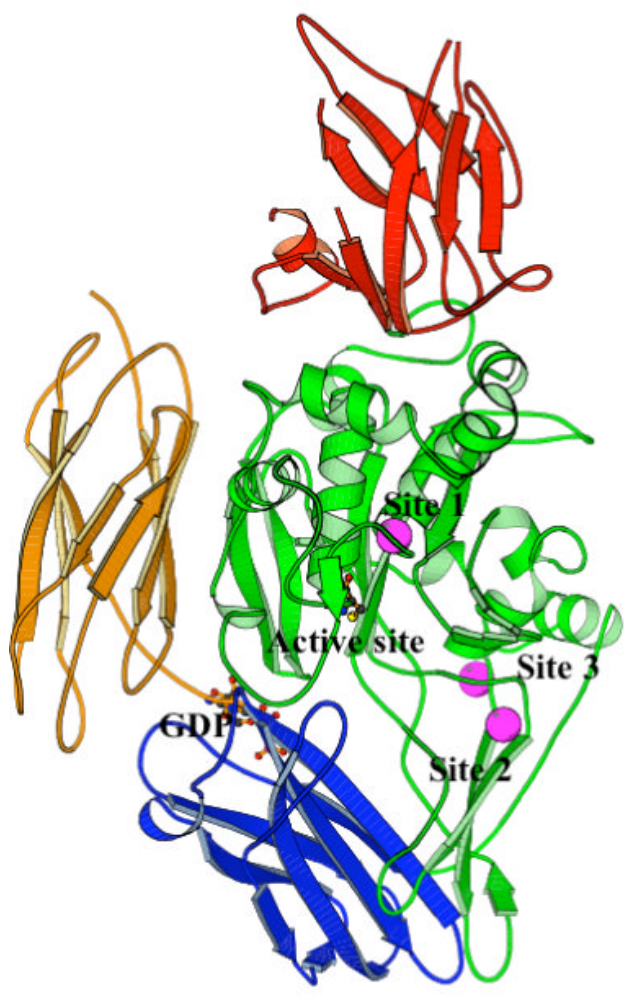

Site 1

\begin{tabular}{|c|c|}
\hline TGII & SGMVNCNDDQGVL \\
\hline TGIII & SAMI NSND DNGVI \\
\hline TGI & SAMVN SLDDNGVL \\
\hline TGIV & CAMMSFEKGQGVL \\
\hline TGV & CAMI N SND DNGVL \\
\hline TGVI & SAMVN SNNDRGVV \\
\hline TGVI I & SAMI NSNDDNGVL \\
\hline XIIIA_Pre & SAMVNAKDDEGVL \\
\hline
\end{tabular}

Site 2

$\begin{array}{ll} & \\ \text { TGII } & \text { SAHDQNSNLLI } \\ \text { TGIII } & \text { SAHDTDRNLSV } \\ \text { TGI } & \text { SAHDTDTSLTM } \\ \text { TGIV } & \text { SAHDTERNLTV } \\ \text { TGV } & \text { SGHDTDGNLII } \\ \text { TGVI } & \text { SAHDTDQNLSV } \\ \text { TGVII } & \text { SAHNVDRNLTI } \\ \text { XIIIA_Pre } & \text { SAHDNDANLQM }\end{array}$

Site 3

TGI I
TGI II
TGI
TGIV
TGV
TGVI
TGVII

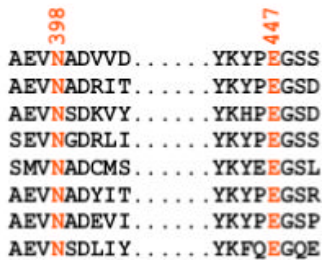




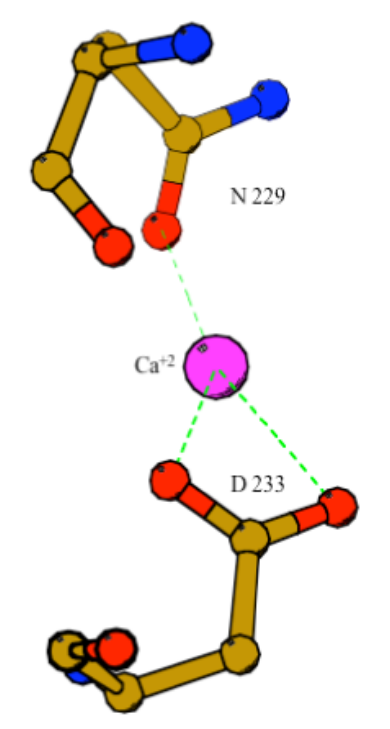

Site 1

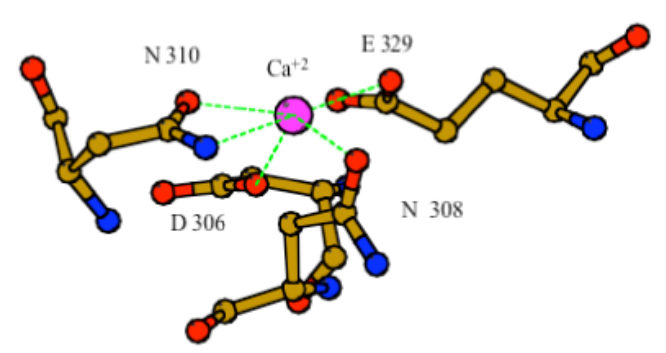

Site 2

Site 3

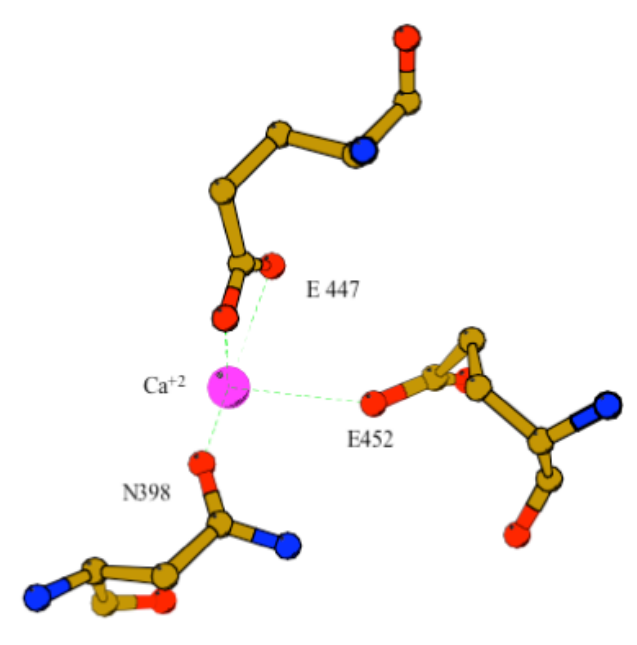

Figure 1.

$\mathrm{Ca}^{2+}$-binding sites on TGase-II. (A) Structural depiction of TGase-II showing $3 \mathrm{Ca}^{2+}$-binding sites, the transamidation active site and the guanine nucleotide-binding site. The $\mathrm{N}$-terminal $\beta$-sandwich domain, the catalytic core domain, and the first and second $\beta$-barrel domains are shown in red, green, blue and yellow, respectively. Cysteine 277 within the active site and GDP are shown as ball-and-stick models; $\mathrm{Ca}^{2+}$ ions are depicted as spheres. The $\mathrm{Ca}^{2+}$-binding sites were derived by superposing the X-ray structure for TGase-II onto the structure for TGase-III. Sequence alignments using the program Clustal W (44) are also presented for each of the $\mathrm{Ca}^{2+}$-regulatory sites of TGase-II, versus TGase-III and other members of the transglutaminase family that show $\mathrm{Ca}^{2+}$-dependent transamidation activity. The numbered residues in orange represent the sites mutated in TGase-II. (B) Residues proposed to interact with $\mathrm{Ca}^{2+}$ at sites 1, 2 and 3 of TGase-II are labeled. Interactions, represented by broken lines, were derived from the TGase-III structure. 


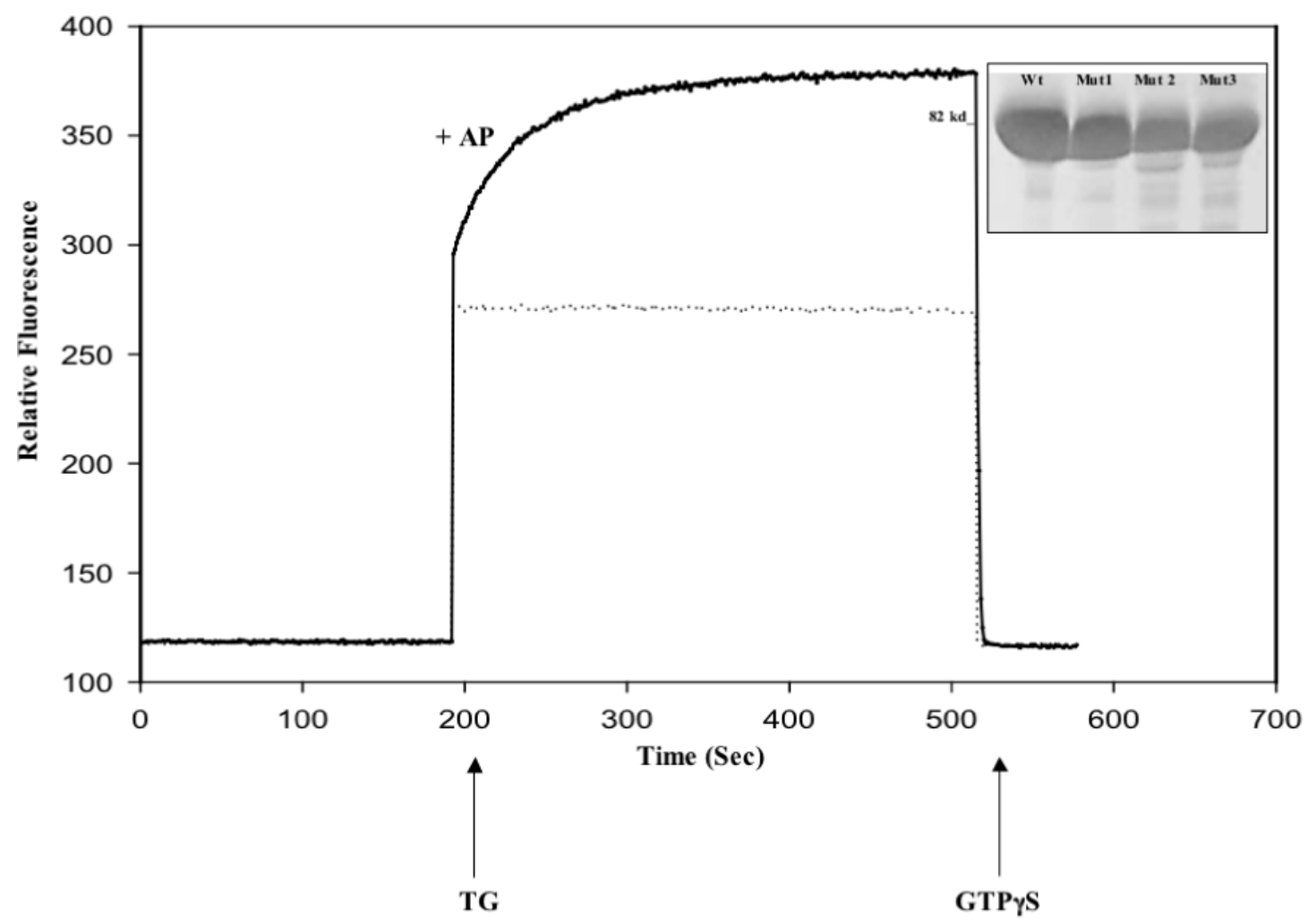



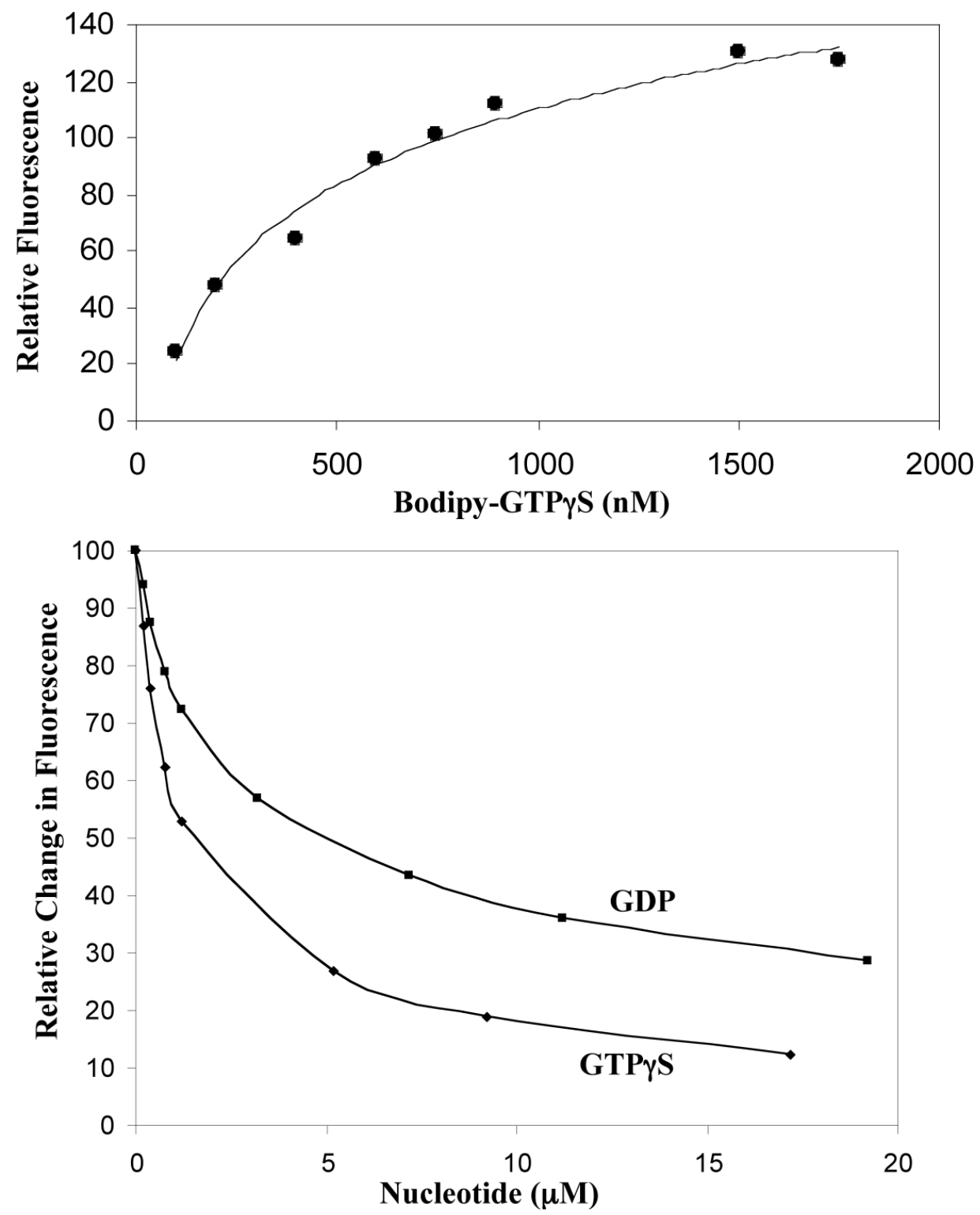

Figure 2.

Binding of BOD-GTP $\gamma$ S to wild-type TGase-II. (A) BOD-GTP $\gamma \mathrm{S}(380 \mathrm{nM})$, dissolved in a buffer containing $50 \mathrm{mM}$ Tris-HCl, $\mathrm{pH}$ 7.5, $1 \mathrm{mM}$ EDTA, and $2 \mathrm{mM}$ DTT, was used to obtain a baseline fluorescence emission at $520 \mathrm{~nm}$ (excitation $=504 \mathrm{~nm})$. After 3 minutes, wild-type TGase-II $(190 \mathrm{nM})$ was added to the reaction cuvette. The horizontal dashed line shows the enhancement in BODIPY fluorescence that accompanied the addition of TGase-II. GTP $\gamma \mathrm{S}$ $(240 \mu \mathrm{M})$ was then added to compete with BOD-GTP $\gamma \mathrm{S}$ and thus decrease the fluorescence emission at $520 \mathrm{~nm} .(+)$ AP represents the increase in fluorescence emission that accompanied the binding of BOD-GTP $\gamma$ S to additional nucleotide-free, wild-type TGase-II molecules generated upon treatment with alkaline phosphate. Inset, SDS-PAGE analysis of purified $E$. coli recombinant, human wild-type His-tagged TGase-II (Wt), His-TGase-II (N229A, D233A) (Site 1), His-TGase-II (D306A, N310A) (Site 2), and His-TGase-II (N398A, E447A) (Site 3). The His-tagged TGase-II proteins were purified by a sequence of three chromatography steps: nickel-affinity chromatography, anion exchange chromatography and size-exclusion chromatography as described in "Experimental Procedures". (B) Wild-type TGase-II (270 nM) 
was dissolved in a buffer containing $50 \mathrm{mM}$ Tris-HCl, $\mathrm{pH}$ 7.5, $1 \mathrm{mM}$ EDTA, $2 \mathrm{mM}$ DTT, and $4 \mathrm{mM} \mathrm{Ca}^{2+}$. Increasing concentrations of BOD-GTP $\gamma \mathrm{S}$ were incubated with the protein at room temperature. The relative change in fluorescence $($ emission $=520 \mathrm{~nm}$, excitation $=504 \mathrm{~nm}$ ) accompanying each addition of BOD-GTP $\gamma \mathrm{S}$ was determined after 1 hour. (C) Competition between BOD-GTP $\gamma \mathrm{S}$ and either GTP $\gamma \mathrm{S}$ or GDP, as read-out by changes in BODIPY fluorescence. Wild-type TGase-II ( $300 \mathrm{nM})$, BOD-GTP $\gamma \mathrm{S}(1.8 \mu \mathrm{M})$, and $4 \mathrm{mM} \mathrm{CaCl}_{2}$ were incubated in the Tris-buffer described in 2B for 1 hour. Increasing concentrations of GTP $\gamma \mathrm{S} /$ GDP were added over time. Each addition was followed by a 2 minute equilibration and then the corresponding change in fluorescence was recorded. 

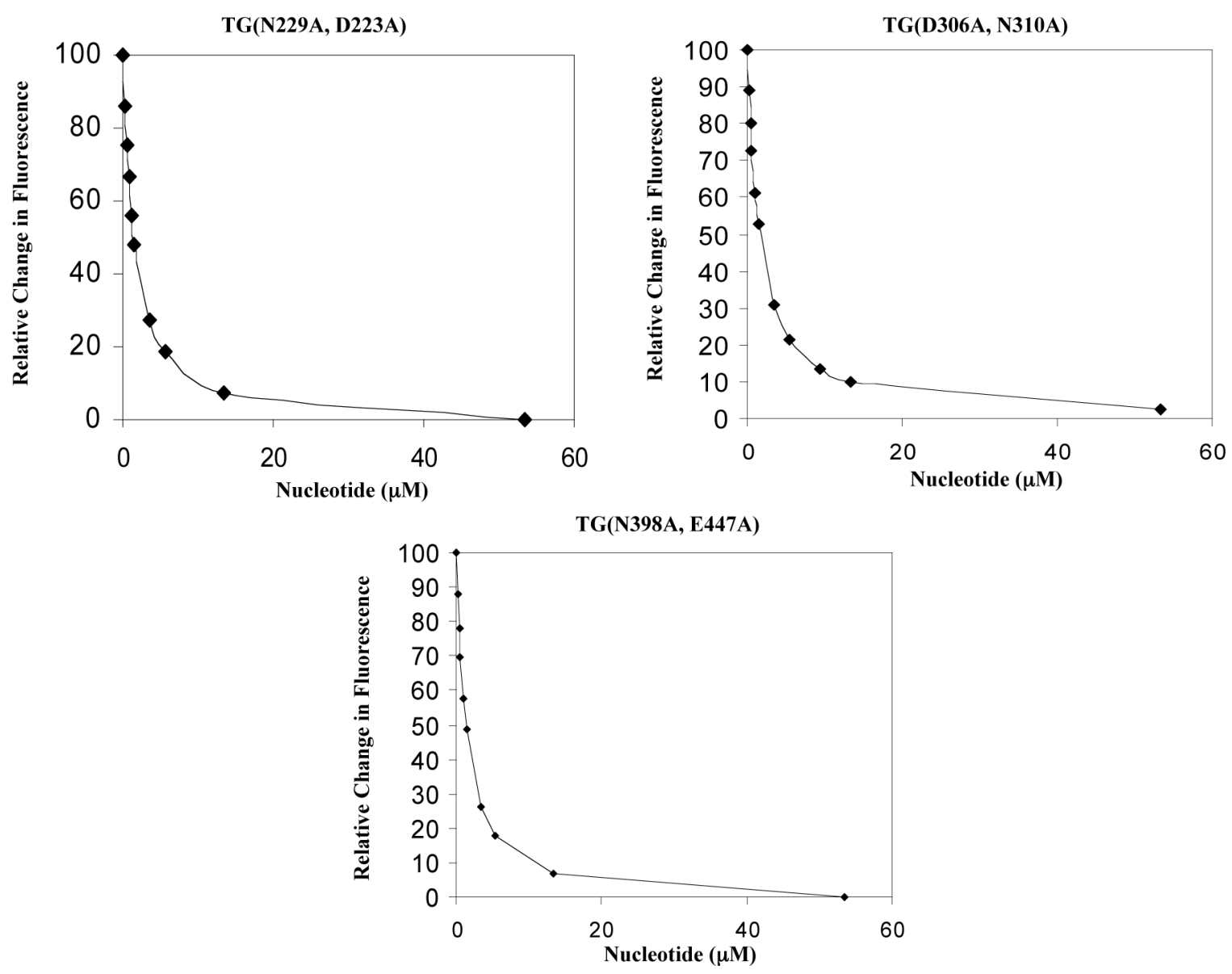

Figure 3.

Binding of BOD-GTP $\gamma \mathrm{S}$ to the different TGase-II mutants. Competition experiments between BOD-GTP $\gamma$ S and GTP $\gamma$ S, like those described in Figure 2C, were performed with TGase-II (N229A, D233A) (A), TGase-II (D306A, N310A) (B), and TGase-II (N398A, E447A) (C). 


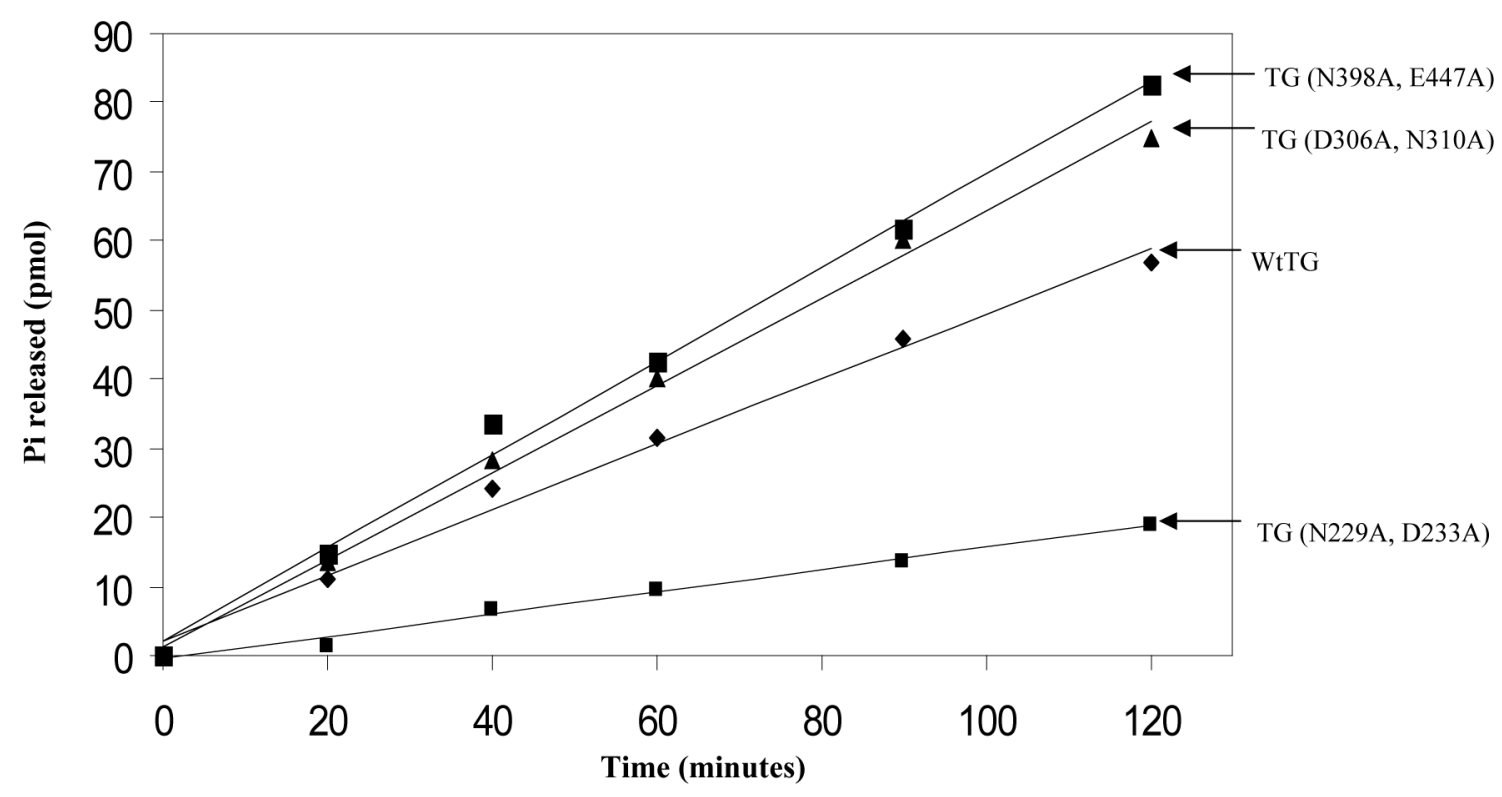

Figure 4.

GTP hydrolytic activity of wild-type TGase-II and the different TGase-II mutants. Wild-type TGase-II (300 nM), or equivalent amounts of each of the TGase-II mutants, were assayed for GTP hydrolytic activity at the indicated times in a buffer containing $200 \mathrm{mM}$ MOPS, $\mathrm{pH} 7.3$, $2 \mathrm{mM} \mathrm{MgCl}_{2}, 100 \mu \mathrm{M}$ EDTA, and $2 \mathrm{mM}$ DTT. Assays were initiated by the addition of $\left[\gamma^{32} \mathrm{P}\right] \mathrm{GTP}$ and the amount of ${ }^{32} \mathrm{Pi}$ (product) generated was determined as described in "Experimental Procedures". 

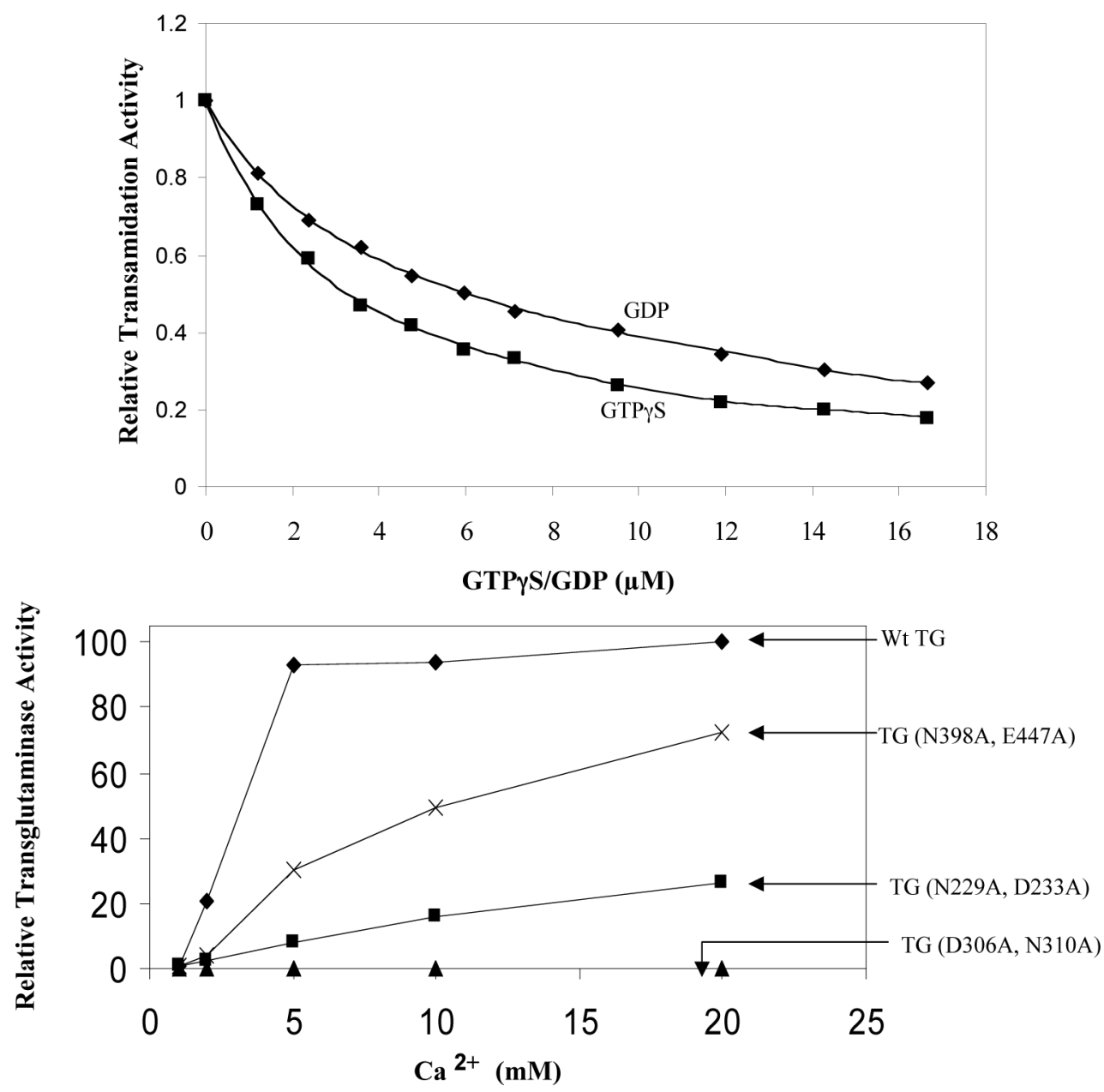


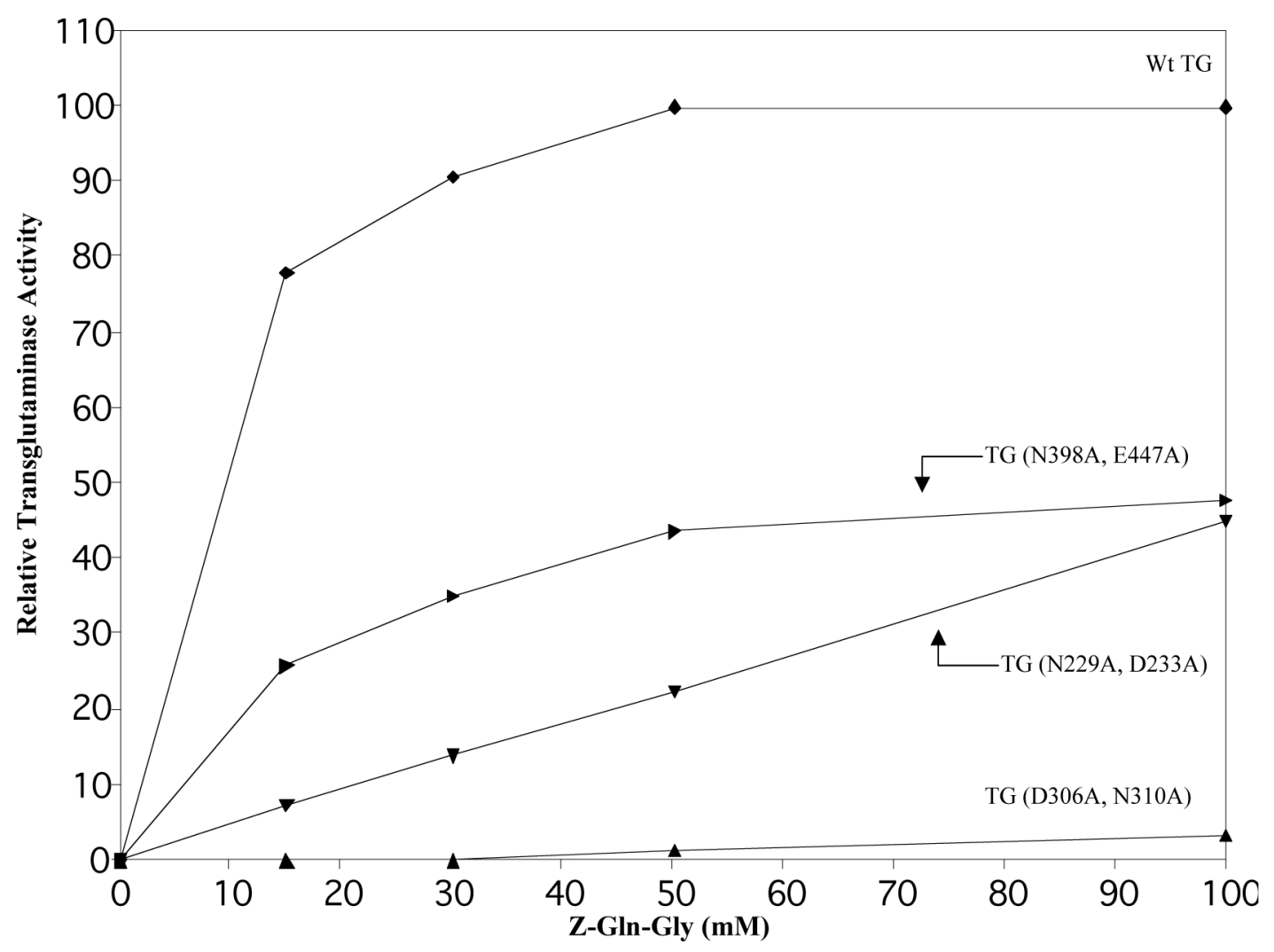

Figure 5.

Assays of the $\mathrm{Ca}^{2+}$-dependent transamidation activity of wild-type TGase-II and the different TGase-II mutants. (A) Increasing concentrations of GTP $\gamma$ S or GDP were incubated with wildtype TGase-II (600 nM), prior to assaying transamidation activity using a colorimetric assay as described in "Experimental Procedures". The transamidation reaction generated $\mathrm{NH}^{+}{ }_{4}$ ions which were used by glutamine dehydrogenase to oxidize NADH to NAD, as followed by measuring the change in absorbance at $340 \mathrm{~nm}$. The initial velocity of the transamidation reaction was calculated from the slope of the linear portion of the curve. Initial velocities were then plotted as relative activities versus increasing concentrations of GTP $\gamma$ S or GDP. (B) The transamidation activities for wild-type TGase-II and the different TGase-II mutants were determined at the indicated $\mathrm{Ca}^{2+}$ concentrations, as described in (A) and in "Experimental Procedures". (C) The transamidation activities for wild-type TGase-II and the different mutants were assayed as a function of the indicated amounts of the glutamine-containing substrate $\mathrm{Z}$ Gln-Gly and at a fixed concentration of $\mathrm{Ca}^{2+}(10 \mathrm{mM})$. 

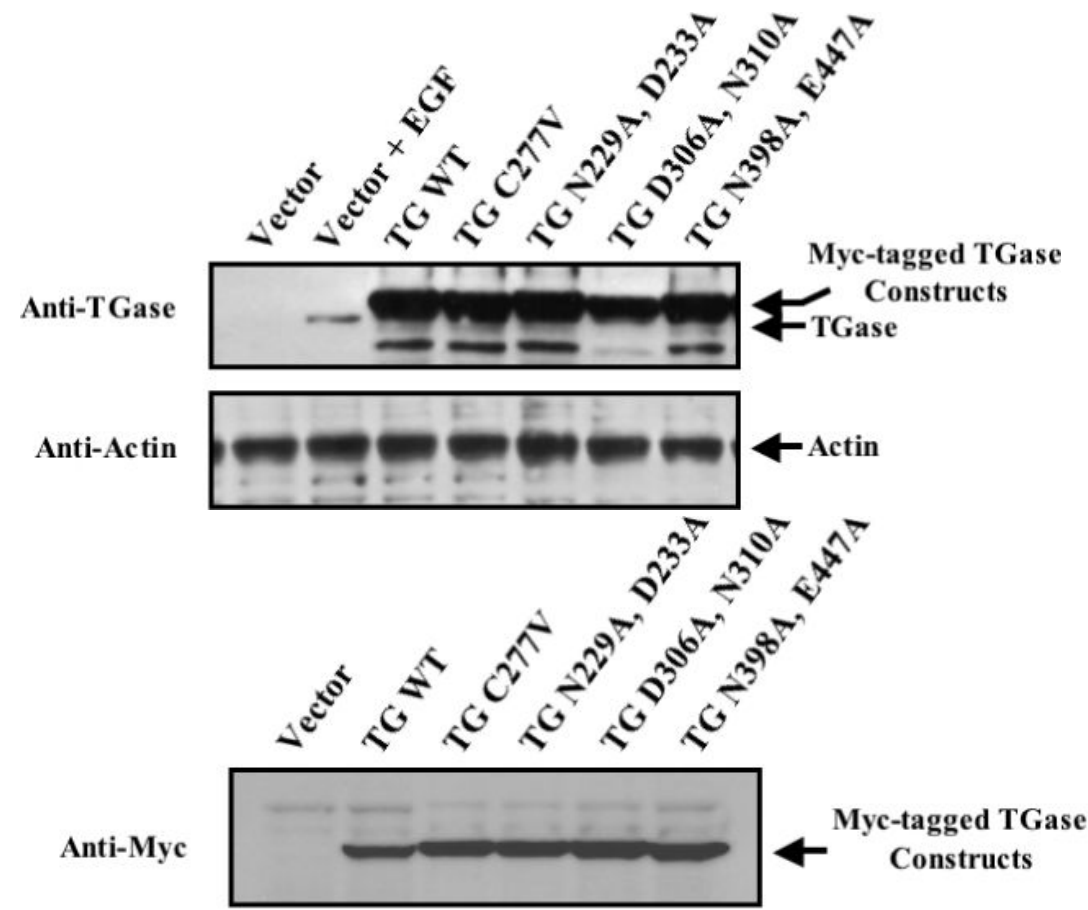

Anti-Actin
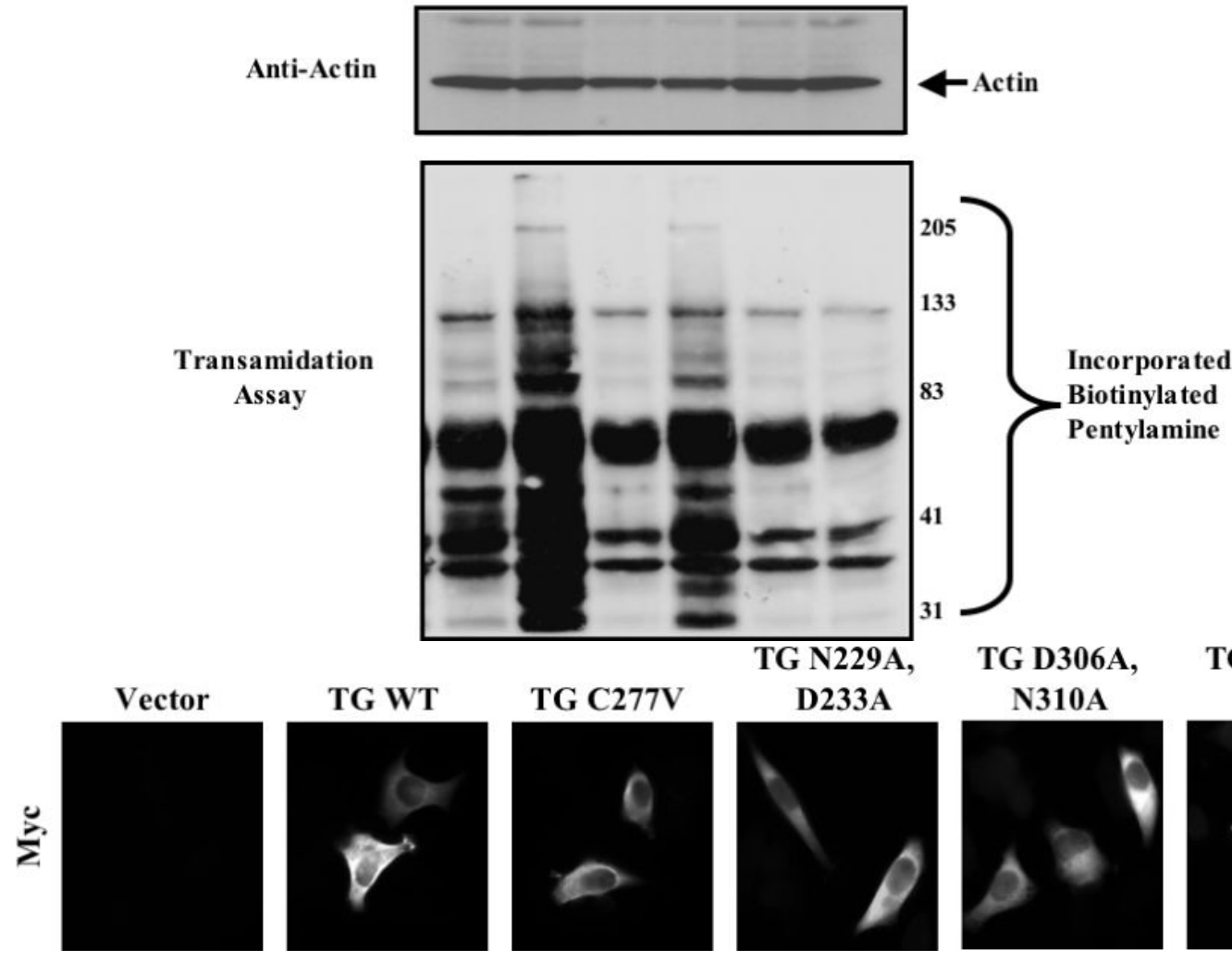

TG N398A, E447A

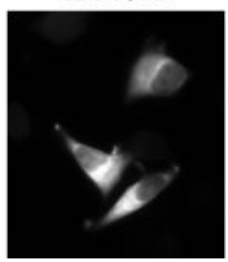



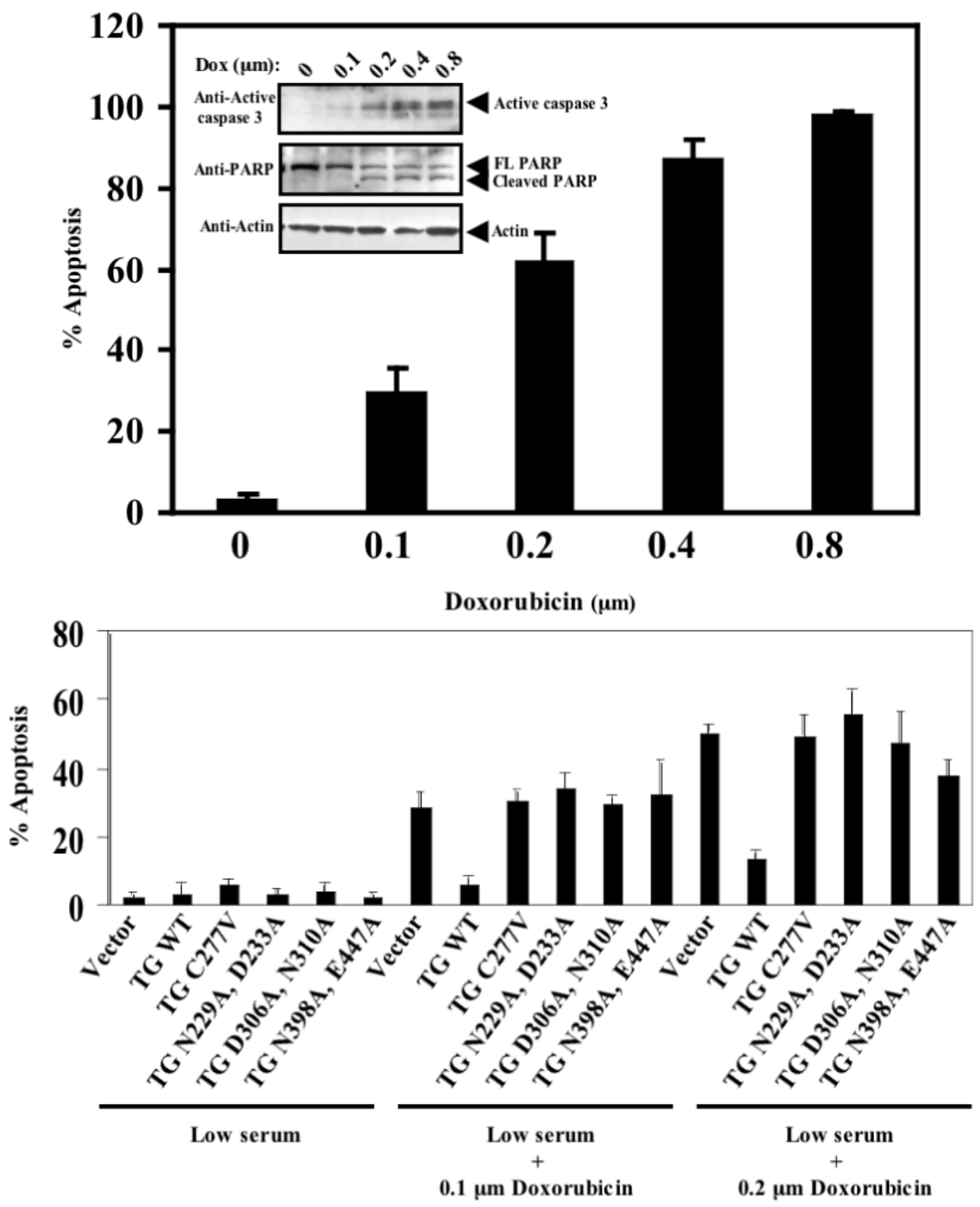

Figure 6.

The $\mathrm{Ca}^{2+}$-binding defective mutants of TGase-II are compromised in their ability to protect SKBR3 cells from doxorubicin-induced apoptosis. SKBR3 cells over-expressing Myc-tagged forms of wild-type TGase-II (TG WT), a TGase-II construct in which cysteine 277 was changed to valine (TG C277V), and the different $\mathrm{Ca}^{2+}$-binding mutants of TGase-II (TG N229A, D233A; TG D306A, N310A; and TG N398A, E447A) were either lysed or fixed. (A) Lysates from vector-control cells treated or untreated with EGF $(100 \mathrm{ng} / \mathrm{ml})$, or lysates from cells expressing the different Myc-TGase-II constructs were subjected to Western blot analysis with anti-TGase-II antibody to determine the relative expression levels of endogenous TGase-II and each of the TGase-II constructs (top panel). The bottom panel shows a loading control using actin. (B) Lysates from vector-control cells or from cells expressing the different Myc-TGaseII constructs were assayed for transamidation activity. The top panel shows the relative 
expression of the different Myc-TGase-II proteins based on Western blot analysis with antiMyc antibody. The second panel from the top shows a loading control using actin. The bottom panel shows the results of transamidation assays, read-out by the incorporation of biotinylated pentylamine into proteins from whole cell lysates prepared from the different transfectants (see "Experimental Procedures"). Numbers on the right-side of the transamidation assay blot indicate positions of molecular weight markers $(\mathrm{kDa})$. (C) Immunofluorescence with an antiMyc antibody was performed on the fixed cells to compare the cellular localization of wildtype Myc-TGase-II and the different Myc-tagged TGase-II mutants. (D) SKBR3 cells were incubated with the indicated levels of doxorubicin for 24 hours and then were scored for apoptosis as identified by nuclear condensation or blebbing. Inset shows the Caspase- 3 activity under the different conditions of drug treatment, as assayed using an antibody that detects activated Caspase-3 and by the proteolytic degradation of PARP. (E) SKBR3 cells overexpressing wild-type TGase-II or the different TGase-II mutants were incubated with either $0.1 \mu \mathrm{M}$ or $0.2 \mu \mathrm{M}$ doxorubicin for 24 hours and then scored for apoptosis. The apoptotic assays were conducted at least three times and the average percentage of cell death was plotted. The error bars indicate standard error. 


\section{Table 1}

Amino acid residues comprising the three $\mathrm{Ca}^{2+}$-regulatory sites on TGase--II ${ }^{a}$.

$\begin{array}{llc}\mathbf{C a}^{2+} \text { atom } & \begin{array}{c}\text { Protein atom } \\ \text { Site } 1\end{array} & \begin{array}{c}\text { Distance (Å) } \\ \text { ASN A229 (OD1) }\end{array} \\ \text { Site } 2 & \text { ASP A233 (OD1) } & 2.4 \\ & \text { ASP A233 (OD2) } & 2.7 \\ & \text { ASN A308 (OD1) } & 3.4 \\ & \text { ASN A310 (ND2) } & 3.5 \\ & \text { ASN A310 (OD1) } & 2.5 \\ \text { Site 3 } & \text { ASP A306 (OD2) } & 2.3 \\ & \text { GLU A329 (OE1) } & 2.2 \\ & \text { GLU A329 (OE2) } & 2.2 \\ & & \\ & \text { ASN A398 (OD1) } & 2.2 \\ & \text { GLU A447 (OE1) } & 2.5 \\ & \text { GLU A447 (OE2) } & 2.7 \\ \text { GLU A452 (OE1) } & 2.9\end{array}$

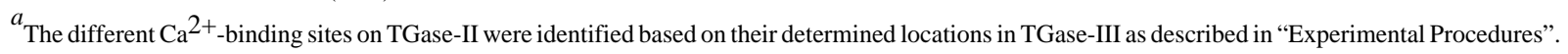
The estimated distances between $\mathrm{Ca}^{2+}$ and the side-chain atoms for each residue (indicated in parentheses) are indicated. 


\section{Table 2}

The ability of guanine nucleotides to bind to TGase-II and inhibit transamidation activity. ${ }^{a}$

\begin{tabular}{|c|c|c|}
\hline \multirow{2}{*}{ Protein } & \multicolumn{2}{|c|}{ Apparent dissociation constant (nM) } \\
\cline { 2 - 2 } & \multicolumn{2}{|c|}{ Nucleotide } \\
\cline { 2 - 2 } & GTP $\gamma$ S & GDP \\
\hline WT & $320 \pm 25$ & $1500 \pm 17$ \\
\hline N229AD233A & $320 \pm 19$ & \\
\hline D306AN310A & $250 \pm 22$ & \\
\hline N398AE447A & $340 \pm 8$ & \\
\hline
\end{tabular}

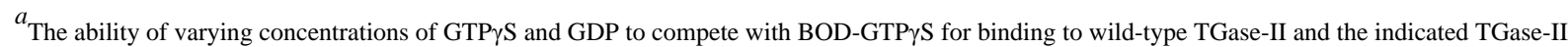
mutants was performed as described in Figure 2C. The apparent dissociation constants were determined from the best fits to the titration data assuming a simple competition between BODIPY-GTP $\gamma \mathrm{S}$ and either GTP $\gamma \mathrm{S}$ or GDP for TGase-II, using the program DYNAFIT (version 3.28.038) (45). 